\title{
Catalysis and Electron Transfer in De Novo Designed Helical Scaffolds
}

Tyler B. J. Pinter, Karl J. Koebke, and Vincent L. Pecoraro*

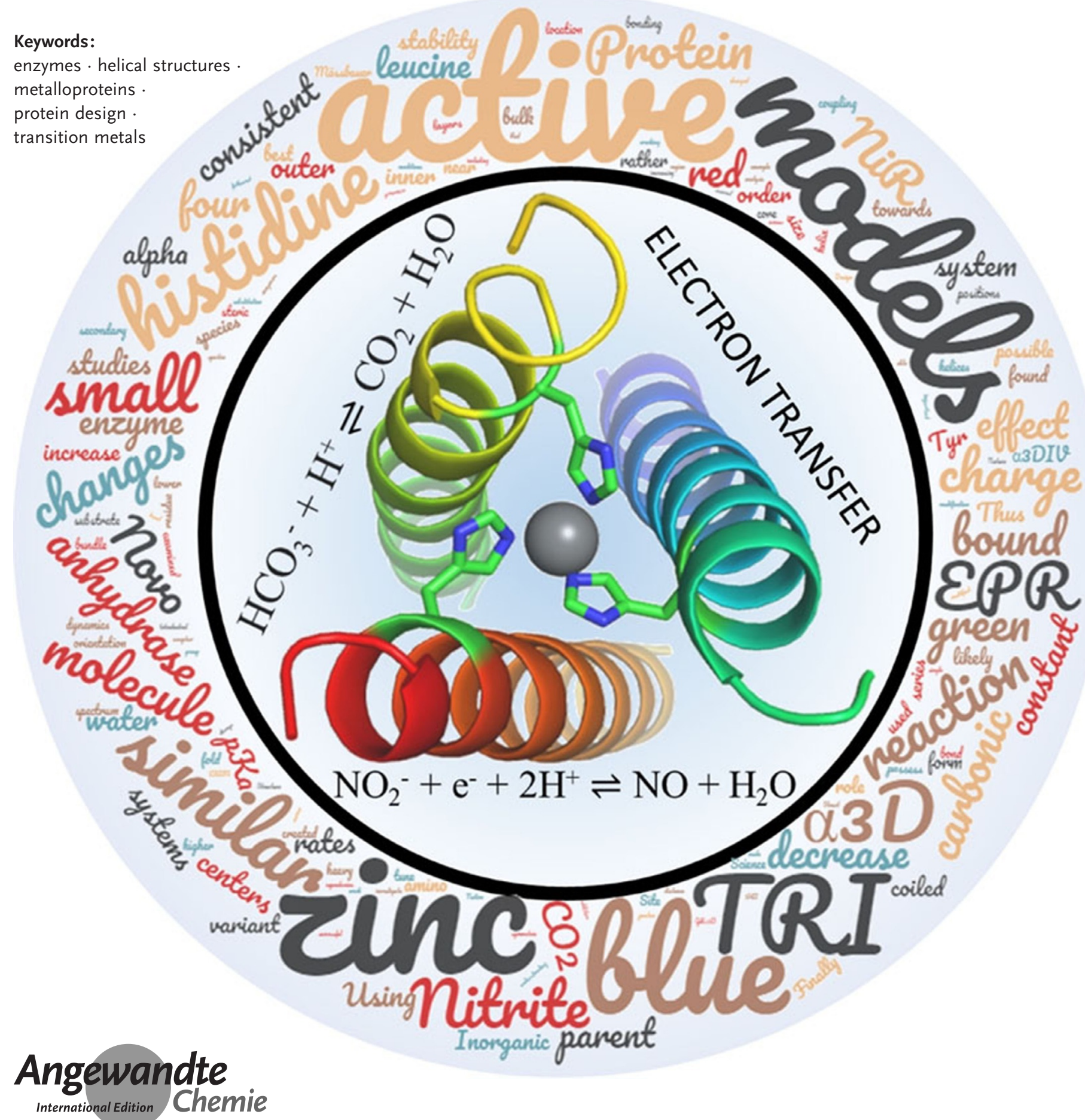


The relationship between protein structure and function is one of the greatest puzzles within biochemistry. De novo metalloprotein design is a way to wipe the board clean and determine what is required to build in function from the ground up in an unrelated structure. This Review focuses on protein design efforts to create de novo metalloproteins within alpha-helical scaffolds. Examples of successful designs include those with carbonic anhydrase or nitrite reductase activity by incorporating a $\mathrm{ZnHis}_{3}$ or $\mathrm{CuHis}_{3}$ site, or that recapitulate the spectroscopic properties of unique electron-transfer sites in cupredoxins (CuHis ${ }_{2} \mathrm{Cys}$ ) or rubredoxins $\left(\mathrm{FeCys}_{4}\right)$. This work showcases the versatility of alpha helices as scaffolds for metalloprotein design and the progress that is possible through careful rational design. Our studies cover the invariance of carbonic anhydrase activity with different site positions and scaffolds, refinement of our cupredoxin models, and enhancement of nitrite reductase activity up to 1000-fold.

\section{From the Contents}

\begin{tabular}{l} 
1. Introduction \\
$\begin{array}{l}\text { 2. De Novo Designed } \\
\text { Metallopeptides for Catalysis }\end{array} 7679$ \\
\hline $\begin{array}{l}\text { 3. Development of Copper Centers } \\
\text { as Models of Nitrite Reductase } \\
\text { Activity }\end{array}$ \\
$\begin{array}{l}\text { 4. Design of Electron-Transfer Sites } \\
\text { in De Novo Scaffolds }\end{array}$ \\
\hline \begin{tabular}{l} 
5. Summary and Outlook \\
\hline
\end{tabular}
\end{tabular}

designed by Hodges et al. to mimic coiled-coil tropomycin. ${ }^{[9]}$ TRI consists of repeating heptads (abcdefg) with

\section{Introduction}

Metalloproteins and peptides perform an immense number of the most critically important biochemical reactions required for all life. ${ }^{[1]}$ Some of the most significant of these are the transfer of electrons within biological systems using redox-active metal centers and protein-supported metalfacilitated catalysis. ${ }^{[1 \mathrm{c}, 2]}$ Such significance highlights the extensive and wide range of metals in biological systems that can be tapped to aid in the development of de novo designed systems.

De novo protein design uses a bottom-up approach for the development of a functional protein in scaffolds completely different from native systems. ${ }^{[3]}$ Such a strategy has two equally important and parallel goals. The first goal is that, through recapitulation of native metal binding sites in de novo scaffolds, which generally possess a significantly different secondary structure than the native system, we are challenging the accuracy and completeness of our understanding of the chemical principles and properties that govern the function of metalloproteins. This approach allows the basic requirements of the desired function to be studied, without the additional potentially convoluting "evolutionary baggage" that accompanies the study of native proteins. ${ }^{[4]}$ The second goal is to generate novel catalysts that have improved properties for catalytic applications. ${ }^{[5]}$ There are numerous approaches for the de novo design of a metalloprotein and an even larger number of designed scaffolds to work with. ${ }^{[6]}$ There have been many reviews on the subject of metalloprotein design for catalysis, ${ }^{[3 e]}$ including an entire issue of Accounts of Chemical Research. Therefore, this Review highlights recent developments using purely alpha-helical structures, specifically using three-stranded coiled-coil peptides (3SCCs) and three helix bundle (3HB) proteins, emphasizing research from our group.

There are several advantages to 3SCCs and $3 \mathrm{HB}$ systems. ${ }^{[7]}$ The TRI family of 3SCCs are designed based on CoilSer ${ }^{[8]}$ which itself originated from the polyheptapeptide leucine residues in the first ( $a$ site) and fourth ( $d$ site) positions. ${ }^{[10]}$ The other positions are helix-inducing (Ala, $c$ sites), charged, and/or salt-bridging residues (Lys at $b, g$ sites and Glu at $e, f$ sites). The geometry of a super-coiled alpha helix, with 3.5 residues per turn aligns the leucine residues on one face of the alpha helix, thereby creating an amphiphilic structure. The crystallographic analogue or TRI, CoilSer (CS), is shown in Figure $1 \mathrm{~A}$. In TRI, three alpha helixes associate in a parallel manner and the leucine residues pack together to form a hydrophobic core of $a$ and $d$ residues. Salt bridges between the $e$ and $f$ residues on neighboring strands
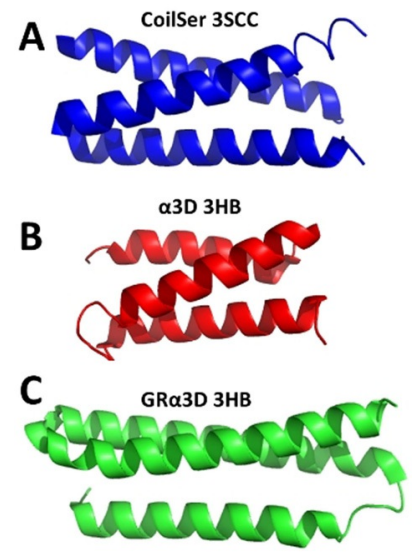

Figure 1. Structures of the peptide and protein scaffolds discussed in this Review: crystallographic TRI analogue CoilSer (A; PDB: 3PB $J^{[12]}$ ), $\alpha_{3} \mathrm{D}$ (B; PDB: $2 \mathrm{MTQ}^{[13]}$ ), and $\mathrm{GR} \alpha_{3} \mathrm{D}$ (C; PDB: 6DS9 ${ }^{[1]]}$ ). Department of Chemistry, University of Michigan Ann Arbor, Michigan, 48109-1055 (USA) E-mail:vlpec@umich.edu

iD The ORCID identification numbers for the authors of this article can be found under: https://doi.org/10.1002/anie.201907502.
[*] Dr. T. B. J. Pinter, Dr. K. J. Koebke, Prof. V. L. Pecoraro 
stabilize the structure. To enhance the stability of the coiled-coil structures, the $\mathrm{N}$-terminus and $\mathrm{C}$-terminus are amidated and acylated, respectively. This arrangement creates layers of leucine residues in the structure's hydrophobic core that can be substituted by metal-binding residues to generate metal binding sites within the TRI scaffold. Table 1 lists the sequences of CS and TRI peptides that will be discussed in this Review.

Three parallel and independent strands must associate in the TRI/CS system to form a metal binding site. This differs significantly from most native metal binding sites, where the metal-chelating residues are all from the same strand. Therefore, a second scaffold was created that links the three alpha helixes together using flexible loops to create $\alpha_{3} \mathrm{D}$, an antiparallel 3HB protein (Figure 1B). However, the de novo design strategy remains the same as for TRI: substitution of hydrophobic core residues or residues near or on the flexible loops with metal-binding residues generates metal binding sites. An additional distinction between TRI and $\alpha_{3} \mathrm{D}$ is that since TRI is formed by the association of three identical strands, only symmetric metal binding sites can be generated. In $\alpha_{3} \mathrm{D}$, however, each amino acid can be independently mutated, thereby allowing complete control over the residues around and within the metal coordination sphere. Finally, to increase the stability of the $3 \mathrm{HB}$ scaffold on increasing the number of destabilizing mutations in the parent scaffold $\alpha_{3} \mathrm{D}$, we designed a lengthened version called Grand $\alpha_{3} \mathrm{D}\left(\mathrm{GR} \alpha_{3} \mathrm{D}\right.$, Figure $1 \mathrm{C}) .{ }^{[11]}$ In this Review, we will describe advances that we have made towards the rational design of both catalytic and electron-transfer metal binding sites within our TRI (including TRI, GRAND, and CoilSer peptides) and $\alpha_{3} \mathrm{D}$ scaffolds (including $\alpha_{3} \mathrm{D}$ and Grand $\alpha_{3} \mathrm{D}$ ).

\section{De Novo Designed Metallopeptides for Catalysis}

Metals catalyze an extremely diverse set of reactions in biological systems. ${ }^{[14]}$ The same metal in different peptidic environments can possess wildly variant activities and display disparate reactions. Iron, for example, plays critical roles in oxygen storage and transport, electron transfer, and numerous hydroxylation, dioxygenation, oxidation, and hydrolysis reactions; each reaction is modulated only by the specific environment in which the metal is located. ${ }^{[15]}$ Thus, by approximate recreation of the positions of specific conserved residues that surround native metal binding sites, we are able to generate desired catalytic activities in our de novo scaffolds. There are three functions that we have had the most success with to date, zinc-catalyzed hydrolysis, nitrite reductase activities, and electron-transfer sites.

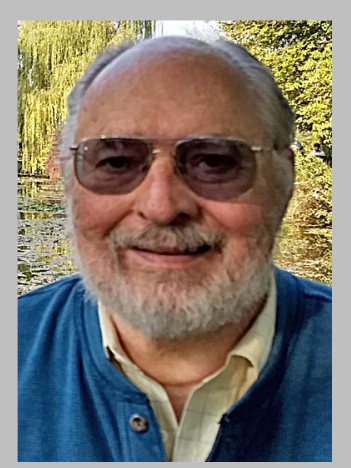

Vincent L. Pecoraro is the John T. Groves Collegiate Professor of Chemistry at the University of Michigan, Ann Arbor (USA). $\mathrm{He}$ is an expert in bioinorganic and supramolecular chemistry, having made substantive contributions to the understanding of photosynthetic water oxidation and vanadium biochemistry. In recent years he has been a leader in the field of metalloprotein design and the development of metallacrowns as biomolecular imaging agents. He served as an Associate Editor for Inorganic Chemistry for over 20 years and is a fellow of both the ACS and AAAS.

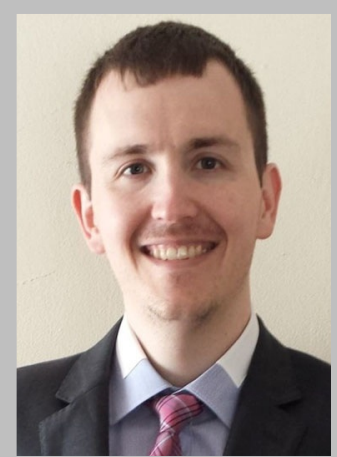

Karl J. Koebke obtained his PhD from the University of Wisconsin-Milwaukee (USA) working with Prof. Andy Pacheco on the kinetics of nitric oxide dioxygenation in heme proteins. He then carried out postdoctoral research for three years with Prof. Vincent Pecoraro, where he designed a plethora of de novo constructs including nitrite reductase and cupredoxin mimics. After a year working with Prof. Timothy Stemmler (Wayne State University) on mitochondrial FeS cluster biogenesis, he is now working with Prof. Neil Marsh (University of Michigan) on selfassembling protein nanocages. 


\subsection{Development of Zinc Sites as Models of Carbonic Anhydrase Hydrolytic Activity}

Building upon our wealth of knowledge on the binding of heavy metals to tris(cysteine) layers in our de novo designed scaffolds ${ }^{[16]}$ we turned our attention to the more complex problem of recreating catalytic metal sites. This is arguably a more ambitious goal, as the design of the metal binding site must not only include the primary coordinating ligands but support access of the substrate for efficient catalysis.

As a first attempt at inserting a catalytically active metal into our scaffolds, we targeted the symmetric tris(histidine) environment of carbonic anhydrase (CA). CA catalyzes the reversible hydration of $\mathrm{CO}_{2}$ (Reaction (1)), and is critical to buffering the $\mathrm{pH}$ value of blood and respiration. Native CA represented a good first target because of the relative simplicity of the metal binding environment as well as its high catalytic activity. ${ }^{[17]}$ Mutating two different leucine layers in the TRI scaffold at each end of the coiled-coil, one with cysteine near the $\mathrm{N}$-terminus and the other with histidine near the C-terminus, gives TRIL9CL23H. Crystallographically, the tris(cysteine) site was shown to bind a $\mathrm{Hg}^{\mathrm{II}}$ ion for structural stability, while the tris(histidine) site supported a zinc ion for catalysis. ${ }^{[12]}$

$\mathrm{HCO}_{3}{ }^{-}+\mathrm{H}^{+} \rightleftharpoons \mathrm{CO}_{2}+\mathrm{H}_{2} \mathrm{O}$

The inclusion of two layers of metal binding residues destabilized the structure compared to the parent TRI system, but the inclusion of the heavy-metal binding site improved the stability beyond that of the nonmutated form. The structural site was shown to increase the stability of the 3SCC significantly through formation of a trigonal $\mathrm{Hg}^{\mathrm{II}}-\mathrm{Cys}_{3}$ structure. A comparison of the crystal structures showed the zinc active site had an extremely similar geometry to that of native CA, including an exogenous water molecule or hydroxide coordinated to the zinc ion, although the orientation of the coordinating imidazole rings differs between the two (Figure 2).

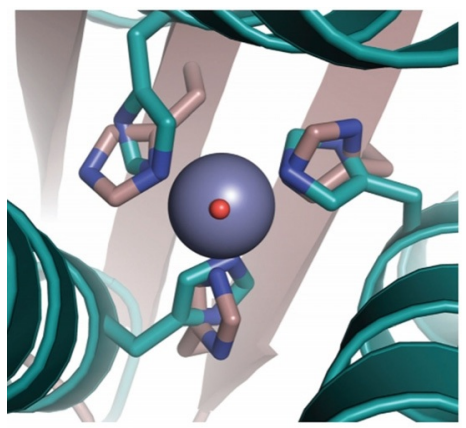

Figure 2. Overlay of the $\mathrm{Zn}^{\prime \prime} \mathrm{N}_{3} \mathrm{O}$ site in $\left[\mathrm{Hg}^{\prime \prime}\right]_{S}\left[\mathrm{Zn}^{\prime \prime}\left(\mathrm{H}_{2} \mathrm{O}\right)\right]_{\mathrm{N}}$ $(\mathrm{CSL9PenL23H})_{3}$ with the active site of human CAII. CS is shown in cyan (PDB: $3 \mathrm{~PB})^{[12]}$ ) and CAll in beige (PDB: $2 \mathrm{CBA}^{[17]}$ ). The solvent molecule associated with $C S$ is shown in red and that associated with CAll lies below the zinc ion. Reprinted from Ref. [12] with permission. Copyright 2012 Nature Publishing Group.
We examined the activity of $\left[\mathrm{Hg}^{\mathrm{II}}\right]_{\mathrm{S}}\left[\mathrm{Zn}^{\mathrm{II}}\right]_{\mathrm{N}}$ TRIL9CL23H (subscripts denote metal-coordinating protein ligands: $\mathrm{HgS}_{3}$ and $\mathrm{ZnN}_{3}$ ) for the hydrolysis of $p$-nitrophenyl acetate (pNPA) and hydration of $\mathrm{CO}_{2}$. The hydrolysis of pNPA is well-studied as a result of the ease of monitoring the formation of the colored $p$-nitrophenolate. Our CA model $\left[\mathrm{Hg}^{\mathrm{II}}\right]_{\mathrm{s}^{-}}$ $\left[\mathrm{Zn}^{\mathrm{II}}\right]_{\mathrm{N}}$ TRIL9CL23H showed a pH-dependent activity (Figure 3, p $K_{\mathrm{a}}$ of hydrolysis ca. 8.8), with a maximum $k_{\mathrm{cat}} /$ $K_{\mathrm{M}}$ value within 100-fold of that of CAII (the isoform with the highest pNPA activity) at $\mathrm{pH} 9.5$. Table 2 compares the activities of our model scaffolds for pNPA hydrolysis. Notably, our CA mimic did not exhibit product inhibition under our conditions, a common issue with small-molecule CA models. ${ }^{[18]}$

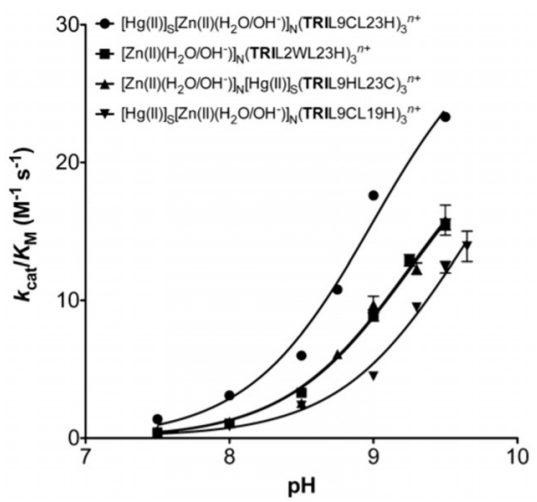

Figure 3. $\mathrm{pH}$-dependence of the catalytic efficiency for pNPA hydrolysis

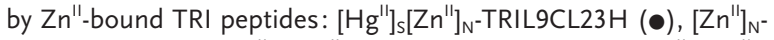

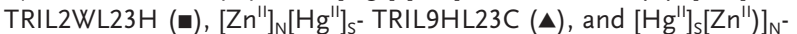
TRIL9CL19H ( $\mathbf{\nabla})$. Reprinted from Ref. [12] with permission. Copyright 2013 American Chemical Society.

Table 2: Kinetic parameters of pNPA hydrolysis by $\mathrm{Zn}$-TRI peptides.

\begin{tabular}{llll}
\hline Peptide scaffold & $\mathrm{p} K_{\mathrm{a}}$ & $k_{\text {cat }} / K_{\mathrm{M}}(\max )\left[\mathrm{M}^{-1} \mathrm{~s}^{-1}\right]^{[\mathrm{a}]}$ & $k_{\text {cat }}(\max )\left[\mathrm{s}^{-1}\right]$ \\
\hline$[\mathrm{Zn}]_{N}(\mathrm{TRIL2WL23H})$ & 9.2 & 25 & 0.055 \\
{$[\mathrm{Hg}]_{S}[\mathrm{Zn}]_{N}(\mathrm{TRIL9CL23H})$} & 9.0 & 31 & 0.053 \\
{$[\mathrm{Zn}]_{N}[\mathrm{Hg}]_{S}(\mathrm{TRIL9HL23C})$} & 9.2 & 24 & 0.030 \\
{$[\mathrm{Hg}]_{S}[\mathrm{Zn}]_{N}(\mathrm{TRIL9CL19H})$} & 9.6 & 27 & 0.076
\end{tabular}

[a] Determined by fitting the $\mathrm{pH}$-dependent $k_{\text {cat }} / K_{\mathrm{M}}$ versus $\mathrm{pH}$ data.

Significantly, this model lacks an important secondary sphere interaction, which plays a significant role in enhancing the rate of $\mathrm{CO}_{2}$ hydration in CAII. T199A mutants of CAII remove a hydrogen-bond acceptor that has been shown to activate the zinc-coordinated water molecule in the mechanism of hydrolysis, ${ }^{[19]}$ thereby reducing the activity approximately 100 -fold versus that of the native enzyme and falling to comparable rates as our CA model. As our $\left[\mathrm{Hg}^{\mathrm{II}}\right]_{\mathrm{S}^{-}}$ $\left[\mathrm{Zn}^{\mathrm{II}}\right]_{\mathrm{N}}$ TRIL9CL23H only reproduced the primary coordination sphere, we had essentially mimicked the activity of CAII T199A.

When we examined the rate constants of the $\mathrm{CO}_{2}$ hydration activity, the native reaction of CAII, $\left[\mathrm{Hg}^{\mathrm{II}}\right]_{\mathrm{S}^{-}}$ $\left[\mathrm{Zn}^{\mathrm{II}}\right]_{\mathrm{N}}$ TRIL9CL23H showed rates within 500 -fold of the native enzyme at $\mathrm{pH} 9.5$, outperforming the best small- 
Table 3: Kinetic parameters of $\mathrm{CO}_{2}$ hydration by enzymes, small molecules, and our model scaffolds.

\begin{tabular}{|c|c|c|c|c|c|c|c|}
\hline Enzyme/ Model & $\mathrm{pK} K_{\mathrm{a}}$ & $\mathrm{pH}$ & $k_{\text {cat }}\left[\mathrm{s}^{-1}\right]$ & $K_{\mathrm{M}}[\mathrm{mm}]$ & $k_{\text {cat }} / K_{\mathrm{M}}\left[\mathrm{L} \mathrm{mol}^{-1} \mathrm{~s}^{-1}\right]$ & $k_{2}\left[\mathrm{~L} \mathrm{~mol}^{-1} \mathrm{~s}^{-1}\right]$ & Ref. \\
\hline CAII & $6.8^{[a]}$ & 8.8 & $8.2 \times 10^{5}$ & 8.9 & $9.2 \times 10^{7}$ & & [25] \\
\hline CAIII & 8.5 & 9.0 & $8 \times 10^{3}$ & 20 & $4 \times 10^{5}$ & & {$[26]$} \\
\hline TRIL9CL23H & $8.82^{[b]}$ & 9.5 & $1.8 \times 10^{3}$ & 10.0 & $1.8 \times 10^{5}$ & & [12] \\
\hline$\alpha_{3} \mathrm{DH} 3$ & 9.4 & 9.5 & $1.3 \times 10^{2}$ & 3.5 & $3.8 \times 10^{4}$ & & {$[24]$} \\
\hline Zn"([14]aneN4) & 9.8 & & & & & $5040^{[c]}$ & [27] \\
\hline $\mathrm{Zn}^{\prime \prime}([12] \mathrm{aneN} 4)$ & 8.1 & & & & & 3012 & [18a] \\
\hline Zn"(nitrilotris(2-benzimidazolylmethyl-6-sulfonate) & 8.3 & & & & & 2180 & {$[28]$} \\
\hline Zn"(tris (4,5-di-n-propyl-2-imidazolyl)phosphine) & 8.0 & & & & & 2480 & [29] \\
\hline
\end{tabular}

[a] Taken from Ref. [30]. [b] p $K_{\mathrm{a}}$ of pNPA hydrolysis. [c] pH-independent second-order rate constant (maximal rate) calculated using p $K_{\mathrm{a}}=9.8$ and the measured rate of $690 \mathrm{M}^{-1} \mathrm{~s}^{-1}$ at $\mathrm{pH} 9.0$

molecule CA model by over 70 -fold (Table 3 ). Since our study was reported, models with higher pNPA activities have been described, such as MID1, which showed a maximum $k_{\text {cat }} / K_{\mathrm{M}}$ of $660 \mathrm{M}^{-1} \mathrm{~s}^{-1}$ at $\mathrm{pH} 9 .^{[20]}$ To date, $\left[\mathrm{Hg}^{\mathrm{II}}\right]_{\mathrm{S}}\left[\mathrm{Zn}^{\mathrm{II}}\right]_{\mathrm{N}}$ TRIL9CL23H retains the title of the model with the highest $\mathrm{CO}_{2}$ hydration activity. This study was a keystone work, showing what could be achieved with our de novo scaffolds that reproduce only the first coordination sphere.

\subsection{Impact of the Position of the Zinc Binding Site on the Hydrolytic Activity}

There is the possibility that the presence of the second metal site $\left[\mathrm{Hg}^{\mathrm{II}}\right]_{\mathrm{S}}$ enhanced the activity of our CA model by altering the fraying or "breathing" of the individual strands of the 3SCC. We therefore examined models that lacked the stabilizing tris(cysteine) heavy-metal binding site. ${ }^{[21]}$ When the Cys layer was removed, TRIL23H denaturation studies demonstrated that the $3 \mathrm{SCC}$ was less stable, although the zinc affinity was unaffected. The activity of this model to pNPA was nearly identical to that of $\left[\mathrm{Hg}^{\mathrm{II}}\right]_{S}\left[\mathrm{Zn}^{\mathrm{II}}\right]_{\mathrm{N}}$ TRIL9CL23H except at high $\mathrm{pH}$ values, which we attributed to decreased stability caused by the loss of the stabilizing $\left[\mathrm{Hg}^{\mathrm{II}}\right]_{\mathrm{S}}$ site under more basic conditions

To determine whether the specific location of the metal binding site plays a significant role in the resulting activity, we next designed CA models that modified the position of the zinc site within the leucine-layered core of our 3SCC design. For example, the orientation of the coordinating histidine residues and the resulting placement of the zinc ion has the potential to significantly influence both solvent and substrate access, as well as hydrogen-bonding interactions-factors known to play significant roles in the activity of native CAs. ${ }^{[22]}$ Our scaffolds offer a significant advantage over designing metal binding sites in native or more complex scaffolds as the inclusion of the metal binding site a) does not significantly alter the scaffold geometry, b) can be moved to different positions in the 3SCC by simply changing the location of leucine substitutions, and c) can be placed in a number of approximately geometrically equivalent positions along the $3 \mathrm{SCC}$ as a result of the presence of multiple leucine layers.

We developed the inverted complement to $\left[\mathrm{Hg}^{\mathrm{II}}\right]_{\mathrm{s}}$ $\left[\mathrm{Zn}^{\mathrm{II}}\right]_{\mathrm{N}}$ TRIL9CL23H- $\left[\mathrm{Hg}^{\mathrm{II}}\right]_{\mathrm{S}}\left[\mathrm{Zn}^{\mathrm{II}}\right]_{\mathrm{N}}$ TRIL9HL23C-by placing the zinc active site towards the $\mathrm{N}$-terminus. ${ }^{[21]}$ This construct has a 10-fold lower zinc affinity than TRIL9CL23H and TRIWL23H at $\mathrm{pH} 7.5$ and a 4-fold weaker activity at $\mathrm{pH}$ 9, thus highlighting the importance of the position and orientation of the metal site in the de novo scaffolds. Kinetic analysis of pNPA hydrolysis under Michaelis-Menton conditions showed the inverted construct had a reduced $k_{\text {cat }}$ value of $0.020 \mathrm{~s}^{-1}$ at $\mathrm{pH} 9.5$ (half that of TRIL9CL23H). This decrease in $k_{\text {cat }}$ was, in part, counteracted by a smaller $K_{\mathrm{M}}$ value so $k_{\text {cat }} / K_{\mathrm{M}}$ only decreased from 23.3 to $15.8 \mathrm{M}^{-1} \mathrm{~s}^{-1}$ (Table 2).

Earlier, we had shown that the position of the heavy-metal binding tris(thiolate) site possessed different properties if it were placed at the $a$ site versus a $d$ site within the heptad; for example, the $\mathrm{p} K_{\mathrm{a}}$ value, coordination number, and ligand positions change for cadmium and mercury in these sites. ${ }^{[23]}$ Hypothesizing a similar effect could exist for zinc in tris(histidine) sites, TRIWL9CL19H was studied. This construct showed a fivefold decreased affinity for zinc and an increased $\mathrm{p} K_{\mathrm{a}}$ value for pNPA hydrolysis of 9.6 (from 9.2 in TRIL9CL23H; Figure 3). The construct also showed comparable pNPA hydrolysis rates with $k_{\text {cat }} / K_{\mathrm{M}}$ values similar to those of TRIL9CL23H and TRIL9HL23C, but with an increase in the $K_{\mathrm{M}}$ value to $2.8 \mathrm{~mm}$. These results demonstrate the potential to tune the $K_{\mathrm{M}}$ and $\mathrm{p} K_{\mathrm{a}}$ values by repositioning the metal binding site, with the catalysis largely unaffected. The location of the metal site in a de novo designed scaffold should be based on the ease of incorporating secondary sphere interactions that enhance the reaction rate.

\subsection{Development of a Hydrolytic Zinc 3HB Protein}

The intrinsic symmetry of our self-assembling 3SCC scaffold has numerous benefits, as already discussed above. However, to design a functional hydrogen-bonding network and to model the asymmetry in the second coordination sphere of CAII, we next designed a model of CA in our $\alpha_{3} \mathrm{D}$ type scaffold. ${ }^{[24]}$ Replacement of three of the core leucine layers on the $\mathrm{C}$-terminal side of the original $\alpha_{3} \mathrm{D}$ along with a $\mathrm{H} 72 \mathrm{~V}$ mutation to remove any possible unintended zinc coordination gave $\alpha_{3} \mathrm{DH} 3$. Zinc binds tighter to this threehelix bundle peptide than any $3 \mathrm{SCC}$ model, with an apparent $K_{\mathrm{d}}=0.15 \mu \mathrm{M}$ at $\mathrm{pH} 7.5$ and $0.06 \mu \mathrm{M}$ at $\mathrm{pH} 9$ (TRIL9CL23H: $K_{\mathrm{d}}=0.8 \mu \mathrm{M}$ at $\mathrm{pH} 7$ and $0.22 \mu \mathrm{M}$ at $\mathrm{pH} 9$ ). Extended X-ray absorption fluorescence spectroscopy showed the zinc coor- 
dination sphere consisted of three zinc histidine scatterers at a distance of $1.99 \AA$ and one zinc-oxygen scatterer at a distance of $1.90 \AA$. These parameters are nearly identical to those of the native CAII.

As with the TRI 3SCC, the $\mathrm{CO}_{2}$ hydration activity of $\alpha_{3} \mathrm{DH} 3$ showed a $\mathrm{pH}$-dependence. The reaction was analyzed between $\mathrm{pH} 8$ and 9.5, and showed a maximal efficiency at higher $\mathrm{pH}, k_{\text {cat }} / K_{\mathrm{M}}=69000 \mathrm{M}^{-1} \mathrm{~s}^{-1}$. The catalytic $\mathrm{p} K_{\mathrm{a}}$ value was 9.4 , compared to 8.8 for the $3 \mathrm{SCC}$ model. The maximum measured $k_{\text {cat }} / K_{\mathrm{M}}$ value was $38000 \mathrm{M}^{-1} \mathrm{~s}^{-1}$, which is 14 -times faster than the best small-molecule model, but 2.5-times slower than the best TRI 3SCC model, TRIL9CL23H. Again, this model did not display any product inhibition, a significant advantage over small-molecule studies to date. Compared to the native enzyme, $\alpha_{3} \mathrm{DH} 3$ falls within 2400 -fold of the fastest isozyme, CAII (Table 3).

\subsection{Zinc-Catalyzed Hydrolytic Activity in Other Helical Scaffolds}

As mentioned above, other research groups have developed different helical scaffolds that bind zinc ions and have been shown to possess zinc-catalyzed hydrolytic activity. The Kuhlman group developed a zinc-mediated homodimer in a helix-turn-helix motif. The design of the homodimer contains two four-coordinate zinc ions, each supported by a $\mathrm{His}_{3} \mathrm{O}$ binding site. A fourth His ligand (intended as a fourth primary coordinating ligand) creates a small-molecule binding pocket. As with our current generation of CA models, no second-sphere interactions were intentionally designed. MID1-Zn showed an improved hydrolysis of pNPA compared to our TRI scaffold, with a $k_{\text {cat }} / K_{\mathrm{M}}$ of $660 \mathrm{M}^{-1} \mathrm{~s}^{-1}$ at $\mathrm{pH} 9$, which was attributed to the active site cleft being more accessible in the homodimer. Recently, this group described the artificial evolution of the MID1 catalyst, improving upon the hydrolysis of a racemic fluorogenic ester 70000 -fold. ${ }^{[31]}$ A designed metallo- $\beta$-lactamase was described by the Tezcan group that consisted of a tetramer of modified cytochrome cb562, $\mathrm{Zn}_{8}: \mathrm{AB}_{4} \cdot{ }^{[32]}$ The design of this scaffold relies on a zincmediated self-assembling interface, such that four of the eight zinc ions have a purely structural role, while the remaining four are catalytically active. This protein, in addition to conferring the metallo- $\beta$-lactamase activity, also showed good activity towards pNPA, with $k_{\text {cat }} / K_{\mathrm{M}}$ of $32 \mathrm{M}^{-1} \mathrm{~s}^{-1}$ at $\mathrm{pH} 9$. In a similar approach, the Korendovych group showed how short peptides could self-assemble, facilitated by zinc binding to His residues, to form zinc-mediated amyloid fibrils with esterase activity. ${ }^{[33]}$ These zinc-binding amyloid fibrils, which consist of beta sheets rather than alpha helices, can catalyze ester hydrolysis, with a $k_{\text {cat }} / K_{\mathrm{M}} \approx 150 \mathrm{M}^{-1} \mathrm{~s}^{-1}$ at $\mathrm{pH} 9$ and a maximal $k_{\text {cat }} / K_{\mathrm{M}}=360 \mathrm{M}^{-1} \mathrm{~s}^{-1}$ at $\mathrm{pH} 10.3$.

\section{Development of Copper Centers as Models of Nitrite Reductase Activity}

The de novo design of redox-active metalloenzymes is more complicated than that of redox-inactive metal centers, such as the zinc-containing models of $\mathrm{CA}$. The change in the oxidation state of the metal will not only modify the overall electrostatic charge of the binding site, but, generally speaking, different oxidation states possess differing ligand environments and geometric preferences. $\mathrm{Cu}^{\mathrm{I}}$, for example, shows a stronger preference for softer ligands and a lower coordination number than $\mathrm{Cu}^{\mathrm{II}}$. Therefore, the de novo design of redox-active metalloenzymes must consider the coordination environment of both the reduced and oxidized species, in addition to the criteria described above for redox-inactive metals. Fortuitously, our de novo scaffolds offer some significant advantages over small-molecule models, as the geometry of the metal binding site is constrained by the stable folding of the scaffold in the absence of a metal. Additionally, only small reorganizations have been observed upon metal binding to our scaffolds, and are dependent on the location of the site within the scaffold and on the metal being examined. ${ }^{[34]}$ As mentioned above, most of the current small-molecule mimics are only soluble in organic solvents and optimized to bind a single oxidation state of copper. Thus, our scaffolds are wellsuited to model redox-active metalloenzymes.

Recently, we have described several advances in the development of models with copper nitrite reductase (CuNiR) activity. CuNiRs catalyze the reduction of nitrite to nitric oxide through Reaction 2, the second step in the dissimilatory pathway of nitrate to dinitrogen. $\mathrm{CuNiR}$ is a homotrimeric copper enzyme that possesses two copper binding sites, a type 1 electron-transfer copper center $\mathrm{Cu}$ $\left(\mathrm{His}_{2}\right)(\mathrm{Cys})(\mathrm{Met})$, and a type 2 catalytic copper center $\mathrm{Cu}-$ $\left(\mathrm{His}_{3}\right)\left(\mathrm{OH}_{2}\right)$. The catalytic type 2 copper center exists in a distorted tetrahedral environment, intermediate to the preference of the cuprous and cupric species so as to minimize the reorganization energy of the protein in response to changes in the oxidation state. ${ }^{[35]}$ The mechanism of nitrite reduction is well-studied; briefly, nitrite binds to the type 2 catalytic site first, followed by gated electron transfer from the reduced type 1 site to the type 2 site. Proton-coupled electron transfer, facilitated by hydrogen bonding between a histidine (H225) and an aspartate (E98) to water and the bound substrate, facilitate the catalysis. ${ }^{[36]}$ These residues have been shown to be critical for the high activity of native CuNiRs with at least a 100-fold decrease in activity upon their removal.

$\mathrm{NO}_{2}^{-}+\mathrm{e}^{-}+2 \mathrm{H}^{+} \rightleftharpoons \mathrm{NO}+\mathrm{H}_{2} \mathrm{O}$

\subsection{First Generation CuNiR Models}

Noting that the geometry of the zinc site in our CA model $\mathrm{Hg}^{\mathrm{II}} \mathrm{Zn}^{\mathrm{II}}{ }_{\mathrm{N}}$ (TRIL9CL23H) $)_{3}$ was very similar to that of the type $2 \mathrm{Cu}$ center in $\mathrm{CuNiR}$, we first looked at the binding of copper in the tris(histidine) site of TRI 3SCC using the simplified TRIL23H, which lacks the heavy-metal binding tris(cysteine) site $^{[37]}$ An overlay of the zinc site in $\mathrm{Hg}^{\mathrm{II}}{ }_{\mathrm{S}} \mathrm{Zn}^{\mathrm{II}}{ }_{\mathrm{N}}$ (TRIL9CL23H) $)_{3}$ with the copper centers of CuNiRs showed similar ligand geometries, each coordinating the metal through the $\varepsilon$-nitrogen atom of the histidine and with a coordinated water ligand (Figure 4 ). The charge and Lewis acidity of $\mathrm{Zn}^{\mathrm{II}}$ resembles that of $\mathrm{Cu}^{\mathrm{II}}$, and the $\mathrm{d}^{10}$ 


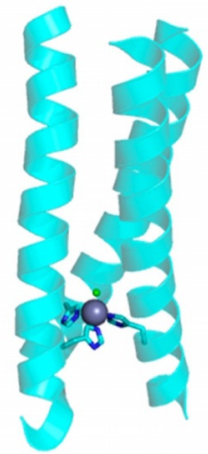

B
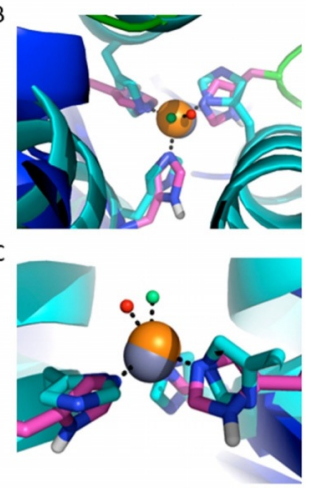

Figure 4. A) Model of $\mathrm{Cu}$-TRIL23H based on the structure of $\mathrm{Hg}^{\prime \prime}{ }_{s} \mathrm{Zn}{ }_{N} \mathrm{CSL9CL23H}$. B) View of the $\mathrm{Zn}^{\prime \prime}\left(\mathrm{H}_{2} \mathrm{O}\right)(\mathrm{His})_{3}$ site along the pseudo-threefold axis (light gray), superimposed on the type 2 $\mathrm{Cu}^{\prime \prime}\left(\mathrm{H}_{2} \mathrm{O}\right)(\mathrm{His})_{3}$ site in NiR from R. sphaeroides (PDB: 2DY2; dark gray). Coordinated water molecules are shown as spheres. C) Side view of the two metal sites, as in (B). Reprinted and adapted from Ref. [37] with permission. Copyright 2012 Proceedings of the National Academy of Sciences of the United States of America.

configuration mimics the electron configuration of $\mathrm{Cu}^{\mathrm{I}}$. Therefore, we were confident that this peptide would be a suitable model of the type 2 site of $\mathrm{CuNiR}$, thus allowing the reaction to be studied in an aqueous environment using the native ligands, unlike small-molecule models, while removing the convolution of the two copper sites in the native $\mathrm{CuNiR}$.

The binding of $\mathrm{Cu}^{\mathrm{I}}$ to the histidine sites was confirmed using ${ }^{1} \mathrm{H}$ NMR spectroscopy. ${ }^{[37]}$ The metal-free apo-TRIL23H showed two singlets in the aromatic region of the ${ }^{1} \mathrm{H}$ NMR spectrum, at $\delta \approx 7.7$ and $7.0 \mathrm{ppm}$, which corresponds to the protons on the $\varepsilon$ - and $\delta$ - nitrogen atoms, respectively. Upon addition of 1 equiv of $\mathrm{Cu}^{\mathrm{I}}$, these singlets gave rise to multiple signals, thus indicating the copper bound specifically to the histidine residues. Additionally, $\mathrm{pH}$ titrations on $\mathrm{Cu}$ TRIL23H monitored by ${ }^{1} \mathrm{H}$ NMR spectroscopy showed the presence of free imidazole protons, consistent with $\mathrm{Cu}^{\mathrm{I}}\left(\mathrm{His}_{3}\right)$, only below $\mathrm{pH} 4.45$. Further characterization using XAS revealed that the $1 \mathrm{~s} \rightarrow 4 \mathrm{p}$ pre-edge feature, the intensity of which can be diagnostic of the coordination number of the copper species, ${ }^{[38]}$ was also consistent with a three-coordinate $\mathrm{Cu}^{\mathrm{I}}$ ion. The EXAFS data for $\mathrm{Cu}^{\mathrm{I}}$ TRIL23H were best fit by three N/O scatterers at a distance of $1.93 \AA$ with additional backscattering at longer distances, characteristic of histidine coordination. The unusually large Debye-Waller factors of these His scatterers suggested a distorted trigonal-planar geometry. The dissociation constant $K_{\mathrm{d}}$ for $\mathrm{Cu}^{\mathrm{I}}$ was determined by competitive titration with bathocuproine disulfonate $\left(\mathrm{BCS}^{2-}\right)$ to be $3.1 \mathrm{pm}$ at $\mathrm{pH} 5.9$ and $0.2 \mathrm{pm}$ at $\mathrm{pH} 7.5$.

$\mathrm{Cu}^{\mathrm{II}}$ binding was investigated by UV/Vis spectroscopy, with a broad absorption observed around $640 \mathrm{~nm}(\varepsilon=$ $\left.135 \mathrm{M}^{-1} \mathrm{~cm}^{-1}\right)$, consistent with a $\mathrm{Cu}^{\mathrm{II}}(\mathrm{His})_{3}$ site containing either one or two exogenous water ligands. ${ }^{[39]}$ The EPR spectrum of $\mathrm{Cu}^{\mathrm{II}}$ TRIL23H was consistent with a five-coordinate type 2 copper center $\left[\mathrm{Cu}^{\mathrm{II}}(\mathrm{His})_{3}\left(\mathrm{H}_{2} \mathrm{O}\right)_{2}\right]$. The addition of nitrite to $\mathrm{Cu}^{\mathrm{II}}$ TRIL23H resulted in a decrease in the $\mathrm{A}_{\|}$ mode (the $z$-axis hyperfine coupling constant) by 9 Gauss, which is indicative of nitrite binding directly to the copper

center, as previously shown for native NiR. ${ }^{[40]}$ The $K_{\mathrm{d}}$ value for $\mathrm{Cu}^{\mathrm{II}}$ of this model was determined by quenching Trp fluorescence to be $40 \mathrm{~nm}$ at $\mathrm{pH} 5.9$ and $8.7 \mathrm{~nm}$ at $\mathrm{pH} 7.5$.

It is possible to calculate the reduction potential of the $\mathrm{Cu}^{\mathrm{I}} / \mathrm{Cu}^{\mathrm{II}}$ couple from the affinities for $\mathrm{Cu}^{\mathrm{I}}$ and $\mathrm{Cu}^{\mathrm{II}}$ using the Nernst equation. The reduction potential for this model is $400 \mathrm{mV}$ at pH 5.9 and $430 \mathrm{mV}$ at $\mathrm{pH} 7.5$, much higher than is typical for type 2 copper centers, ${ }^{[41]}$ and actually falling closer to those reported for type 1 copper centers. This could be due to the trigonal geometry of the $\mathrm{Cu}^{\mathrm{I}}$ state being stabilized in the highly symmetric (His) 3 binding site, thereby raising the reduction potential. Despite this elevated reduction potential, we examined the NiR activity of CuTRIL23H. This model was shown to be capable of generating NO from nitrite, by capture of the produced NO to form the colored FeEDTA(NO). ${ }^{[42]}$ FTIR-GC analysis of the headspace showed no detectable amounts of $\mathrm{N}_{2} \mathrm{O}$, which is a common by-product in other NiR model systems, and represents a significant success with our de novo approach.

Using ascorbate as a sacrificial electron donor, whose signal can be conveniently followed in the UV region at $265 \mathrm{~nm}$ to monitor the reaction, we assayed for NiR activity under catalytic conditions and determined a maximum firstorder rate constant of $4.6 \times 10^{-4} \mathrm{~s}^{-1}$ at $\mathrm{pH}$ 5.8. A significant decrease in the reaction rate as a function of increasing $\mathrm{pH}$ value is likely caused by changes in the $\mathrm{Cu}^{\mathrm{I}} \mathrm{His}_{3}$ coordination environment or the involvement of protons in the nitrite reduction reaction. Although this catalytic rate represents only a modest rate compared to that of the native $\mathrm{CuNiR}$, this model was the only example of a stable, functional $\mathrm{Cu}(\mathrm{His})_{3}$ site in aqueous solution capable of multiple turnovers with no observed decrease in efficiency.

\subsection{Probing the Cu Site}

It is exceptional that our first generation de novo enzymes possess good activities in the absence of any modeling beyond that of the primary metal coordination sphere. Thus, to improve on the CuNiR activity, it was clear that optimization would largely depend on the effect of modifications to the second coordination sphere as well as the electrostatic environment surrounding the copper binding site. ${ }^{[43]}$ Changes to the reaction's free energy barrier $(\Delta G \neq)$, which would result in modification of the enzymatic rates, can be brought about by changes to the electrostatic environment of the active site, through stabilization of charge density in the transition state. Dynamic aspects of enzyme active sites, that is the pico- to microsecond or longer vibrational and translational motions inside and around the catalytic site, are also involved in determining the overall reaction rates. The dynamics and electrostatic factors that drive catalysis can be studied using vibrational probes of enzyme active sites. ${ }^{[44]}$ These studies provide details on the flexibility of the active site, which determines how the substrate accesses the active site and the product is transported away, as well as changes in the reaction barrier with respect to the molecular dynamics around the active site. ${ }^{[45]}$ 
In collaboration with the Kubarych group, we studied the copper environment within our CuNiR model by examining the ultrafast dynamics of carbon monoxide bound to CuTRI$\mathrm{H}$ as a vibrational probe of the $\mathrm{Cu}$ (His) $)_{3}$ environment. ${ }^{[46]} \mathrm{We}$ used two-dimensional IR spectroscopy as an in situ probe of the active site to further connect our understanding of our de novo constructs with that of small-molecule models. ${ }^{[47]}$ The 2D-IR spectrum showed two bands that correspond to the excitation of the ground-state $\left(v=0 \rightarrow 1,2063 \mathrm{~cm}^{-1}\right)$ and excitation of the first excited-state $(v=1 \rightarrow 2$, red-shifted to $2039 \mathrm{~cm}^{-1}$ due to $\mathrm{CO}$ vibrational anharmoncity) transitions. Following vibrational excitation, we observed a time-dependent anharmonicity in the vibrational modes of the bound $\mathrm{CO}$, with a decay constant of 2 ps. The frequency shift brings the two bands closer together, as the $v_{01}$ transition red-shifts and the $v_{12}$ transition blue-shifts. The magnitude of the excited-state blue-shift exceeded that of the ground-state redshift. We also investigated the modified peptide (TRI-H K22Q K24Q), in which six positively charged lysine residues near the copper site are replaced by neutral glutamine groups. This protein exhibited similar anharmonicity as the vibrational transition, thus suggesting that this feature is reproducible in other sequences and is likely common to our other 3SCC scaffolds.

Computer modeling calculations on the full de novo protein were performed to understand the steric and electrostatic interactions that give rise to this behavior. By using a QM/MM ONIOM approach, with the $\mathrm{Cu}$, imidazole ligands, and $\mathrm{CO}$ adduct in the QM (B3LYP/6$311 \mathrm{G}(\mathrm{d}, \mathrm{p})$ ) layer, we observed a $>6^{\circ}$ decrease in the $\mathrm{Cu}-\mathrm{C}-\mathrm{O}$ bond angle of the vibrational excited state. This bending is consistent with the picosecond dynamics observed in the vibrational frequency shifting dynamics and supports that the peptide enhances coupling to the $\mathrm{CO}$ stretch. This result highlights the role of the peptidic environment and is one of the significant advantages of our de novo approach. Further calculations showed that the electric field from the parallel 3SSC peptide scaffold distorts the geometry of the copper-coordinating histidine ligands and is responsible for the $\mathrm{Cu}-\mathrm{C}-\mathrm{O}$ bend coupling to the $\mathrm{CO}$ excited-state stretch, rather than directly affecting the carbonyl group. This coupling to the excited-state bend was strongly dependent on the orientation of the histidine coordination to the copper center, likely a result of the position of the dipole moments (ca. 3.6 D) from each of the individual His ligands (Figure 5). These calculations reveal the role of electrostatics in tuning the molecular dynamics and the energy landscape of ligand coordination within our $\mathrm{Cu}(\mathrm{His})_{3}$ site. Thus, by modification of the electrostatic environment, either by changing the location within the 3SCC (coiled-coil dipole) or by positioning of charged residues in proximity to the site, it is possible to improve our CuNiR.

To improve on this modest CuNiR activity, we then considered the role of the electrostatic environment surrounding the copper binding site first by modification of outer-sphere residues that change the electrostatic environment of the copper center (Figure 6 A), followed by changes to inner-sphere residues (Figure 6B).

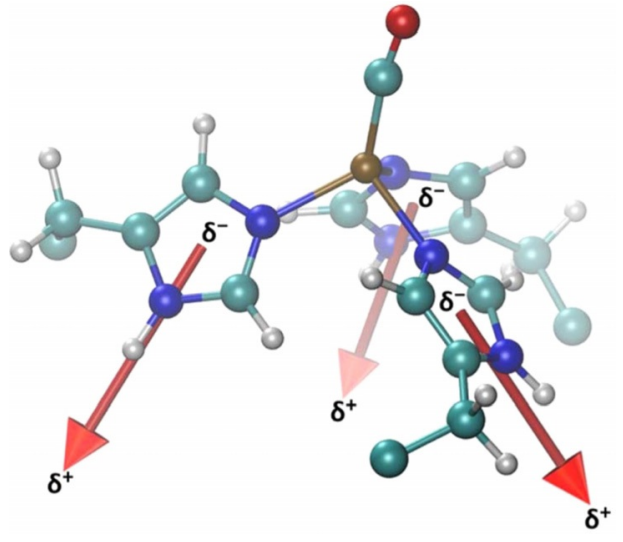

Figure 5. Dipole moment of each histidine ring in $\mathrm{Cu}^{\prime}$ (TRIL2WL23H)3(CO) + with an average magnitude of 3.6 D. These dipolar side chains are able to couple to the electrostatic environment produced by the protein scaffold. Reprinted from Ref. [46] with permission. Copyright 2013 American Chemical Society.

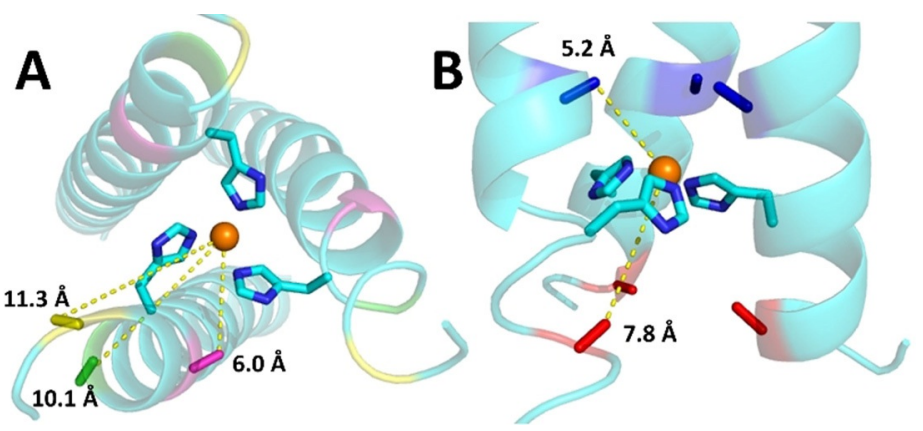

Figure 6. Model of CuNiR highlighting the location of A) outer-sphere and $B$ ) inner-sphere residue substitutions near the $\mathrm{Cu}$ binding site of TRI-H based on the crystal structure of $\mathrm{Zn}^{11}{ }_{N} \mathrm{Hg}{ }_{s}(\mathrm{CSL} \text { PPenL23H) })_{3}$ (PDB: 3PBJ). The copper atom is shown as an orange sphere, distances to the $\beta$-carbon atom of the residues being substituted are indicated for outer-sphere substitutions-K22 (magenta), E24 (green), and K27 (yellow)-and inner sphere-L19 (blue), and L26 (red).

\subsection{Modification of the Charge Density Around the Copper Binding Site}

Modification of the charge density around a redox-active metal binding site (by substituting residues of different charges) will have significant effects on the stability and structure of the different oxidation states, and thus the redox potential, and ultimately the catalytic efficiency or mechanism of redox-active metalloenzyme sites. ${ }^{[48]}$ For example, the protein peptidylglycine $\alpha$-hydroxylating monooxygenase (PHM) has a $\left(\mathrm{His}_{3}\right)$ active site structurally similar to $\mathrm{CuNiR}$, but plays a role in electron transfer instead of being directly involved in catalysis, as is the case for CuNiR. ${ }^{[49]}$ Historically, these studies were performed on native proteins, which bring along the complexity and convoluting factors of native systems. Therefore, we sought to examine the role of the electrostatic environment around the $\mathrm{Cu}$ center in our de novo CuNiR 3SCC model TRI-H by modifying the charge of nearby residues. We designed and synthesized several 
Table 4: Peptide sequences of outer-sphere (upper), inner-sphere (middle), and primary coordinating (lower) residue substitutions for CuNiR activity studies. The position of these modifications can be viewed in Figure 6.

\begin{tabular}{|c|c|c|c|c|c|c|c|}
\hline Peptide $^{[a]}$ & & $a b c d e f g$ & $a b c d e f g$ & $a b c d e f g$ & $a b c d e f g$ & & $\Delta_{\text {charge }}$ \\
\hline TRI-H & $A c-G$ & WKALEEK & LKALEEK & LKALEEK & HKALEEK & $\mathrm{G}-\mathrm{NH}_{2}$ & \\
\hline TRI-HK22Q & $A C-G$ & WKALEEK & LKALEEK & LKALEEQ & HKALEEK & $\mathrm{G}-\mathrm{NH}_{2}$ & -3 \\
\hline TRI-EH & $A c-G$ & WKALEEK & LKALEEK & LKALEEE & HKALEEK & $\mathrm{G}-\mathrm{NH}_{2}$ & -6 \\
\hline TRI-EHE27K & $A C-G$ & WKALEEK & LKALEEK & LKALEEE & HKAKEEK & $\mathrm{G}-\mathrm{NH}_{2}$ & 0 \\
\hline TRI-EHE27Q & $A C-G$ & WKALEEK & LKALEEK & LKALEEE & HKAQEEK & $\mathrm{G}-\mathrm{NH}_{2}$ & -3 \\
\hline TRI-EHK24Q & $A c-G$ & WKALEEK & LKALEEK & LKALEEE & HQALEEK & $\mathrm{G}-\mathrm{NH}_{2}$ & -9 \\
\hline TRI-EHK24E & $A c-G$ & WKALEEK & LKALEEK & LKALEEE & HEALEEK & $\mathrm{G}-\mathrm{NH}_{2}$ & -12 \\
\hline L19l & $A c-G$ & WKALEEK & LKALEEK & LKAIEEK & HKALEEK & $\mathrm{G}-\mathrm{NH}_{2}$ & 0 \\
\hline $\mathrm{L} 19_{\mathrm{D}} \mathrm{L}$ & $A C-G$ & WKALEEK & LKALEEK & LKA $A_{D} L E E K$ & HKALEEK & $\mathrm{G}-\mathrm{NH}_{2}$ & 0 \\
\hline L19A & $A C-G$ & WKALEEK & LKALEEK & LKAAEEK & HKALEEK & $\mathrm{G}-\mathrm{NH}_{2}$ & 0 \\
\hline L26A & $A c-G$ & WKALEEK & LKALEEK & LKALEEK & HKAAEEK & $\mathrm{G}-\mathrm{NH}_{2}$ & 0 \\
\hline L19D & $A C-G$ & WKALEEK & LKALEEK & LKADEEK & HKALEEK & $\mathrm{G}-\mathrm{NH}_{2}$ & -3 \\
\hline L26D & $A c-G$ & WKALEEK & LKALEEK & LKALEEK & HKADEEK & $\mathrm{G}-\mathrm{NH}_{2}$ & -3 \\
\hline $\mathrm{TRI}_{-{ }_{\mathrm{m}} \mathrm{m}} \mathrm{H}$ & $A c-G$ & WKALEEK & LKALEEK & LKALEEK & ${ }_{\delta \mathrm{m}} \mathrm{HKALEEK}$ & $\mathrm{G}-\mathrm{NH}_{2}$ & 0 \\
\hline TRI- ${ }_{\varepsilon m} \mathrm{H}$ & $A c-G$ & WKALEEK & LKALEEK & LKALEEK & ${ }_{\varepsilon m}$ HKALEEK & $\mathrm{G}-\mathrm{NH}_{2}$ & 0 \\
\hline $\mathrm{TRI}_{\varepsilon m} \mathrm{H}$ L19A & $A c-G$ & WKALEEK & LKALEEK & LKAAEEK & ${ }_{\varepsilon m} H K A L E E K$ & $\mathrm{G}-\mathrm{NH}_{2}$ & 0 \\
\hline
\end{tabular}

[a] The $\mathrm{N}$ - and C-termini are acylated and amidated, respectively.

modified peptides with substituted residues, as listed in Table 4 (top), located neither within the hydrophobic interior of the 3SCC (which could lead to significant destabilization) nor directly involved in $\mathrm{Cu}$ coordination (Figure 6 A). ${ }^{[50]}$

The effect of the $\mathrm{pH}$ value on the binding of copper to the outer-sphere-modified peptides was followed using UV/Vis spectroscopy. At a near-neutral $\mathrm{pH}$ value, $\mathrm{Cu}^{\mathrm{II}}-\mathrm{TRI}-\mathrm{H}$ shows a broad band centered at $644 \mathrm{~nm}$, assigned as the d-d transition of the copper atom in the $\mathrm{His}_{3}$ environment. The $\mathrm{pH}$ profiles of the binding of copper to TRI-H are complicated by multiple competing and overlapping processes that occur as a function of the $\mathrm{pH}$ value. The most significant process is the formation of 3SCC, which is known to occur around the $\mathrm{p} K_{\mathrm{a}}$ value of glutamate residues involved in salt bridging at $e$-sites (the fifth position in the heptad repeat) around $\mathrm{pH} 4.5$. Other processes are dependent on the protonation state, charge, and copper-binding propensity of the imidazole ligand ( $\mathrm{pH} 5.5-8)$, as well as the protonation state of any coordinated water molecules $(\mathrm{pH}>8)$. Thus, there are two major changes in the UV/Vis spectrum as a function of the $\mathrm{pH}$ value: a transition associated with 3SCC formation and copper binding to the (His) $)_{3}$ site at low $\mathrm{pH}$ values, which is complete by approximately $\mathrm{pH} 5$, and the deprotonation of the water coordinated to the copper to form a hydroxide with a $\mathrm{p} K_{\mathrm{a}} \approx 8.5$ (Figure 7 ). Other outer-sphere modifications with different charges showed similar $\mathrm{pH}$ profiles for the binding of copper at lower $\mathrm{pH}$ values, but distinctly different profiles at higher $\mathrm{pH}$ values as a result of the various $\mathrm{pH}$ effects coming in to play. TRI-EH, for example, showed a significantly more basic water deprotonation step ( $\mathrm{p} K_{\mathrm{a}}$ 9.86). XAS measurements of the cuprous forms and EPR measurements on the cupric forms of TRI-H and TRI-EH showed no significant difference in the geometry of the copper site between the two scaffolds at $\mathrm{pH}$ 5.8. Minor differences in the intensity of the $\mathrm{Cu}^{\mathrm{I}}$ pre-edge feature and lower Debye-Waller values of the $\mathrm{Cu}-\mathrm{N}$ scatterers in the EXAFS region suggest a slightly more symmetric trigonal- planar geometry for the TRI-EH versus a more distorted Tshaped geometry for the parent TRI-H.
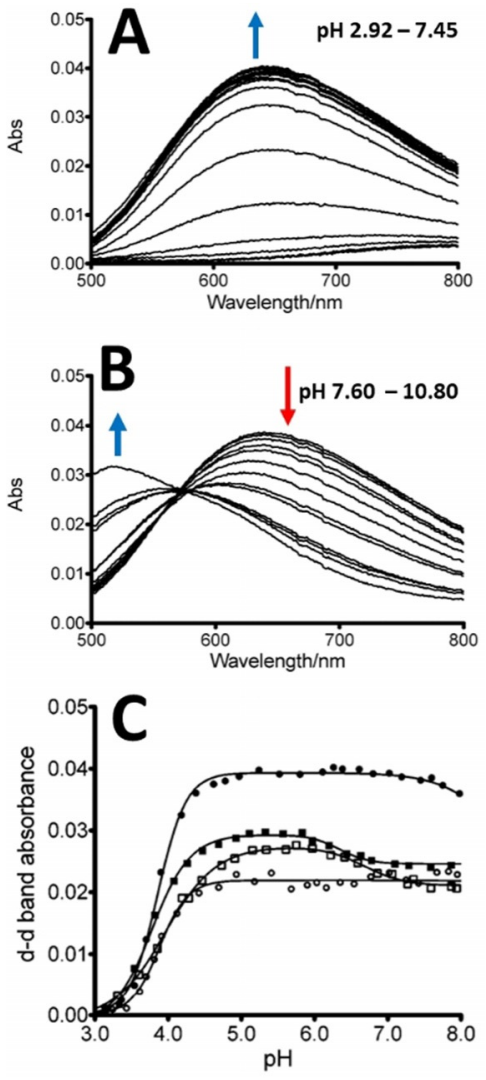

Figure 7. $\mathrm{pH}$ titration of $\mathrm{Cu}^{\prime \prime}(\mathrm{TRI}-\mathrm{H})_{3} \mathrm{~A}$ ) below and $\mathrm{B}$ ) above $\mathrm{pH}$ 7.5. C) Changes in the absorbance of the $\mathrm{Cu}^{\prime \prime} \mathrm{d}-\mathrm{d}$ band when $\mathrm{Cu}$ "l was bound to TRI-H (•; $\Delta$ charge $=0)$; TRI-EHE27K (O; $\Delta$ charge $=0)$; TRI$\mathrm{EH}(\mathbf{\square} ; \Delta$ charge $=-6)$; and TRI-EHK24E $(\square ; \Delta$ charge $=-12)$. Reprinted and adapted from Ref. [50] with permission. Copyright 2013 American Chemical Society. 
Dissociation constants for the $\mathrm{Cu}^{\mathrm{I}}$ and $\mathrm{Cu}^{\mathrm{II}}$ states of the models were measured for the series of models with outersphere modifications. The $K_{\mathrm{d}}$ value for $\mathrm{Cu}^{\mathrm{I}}$ was found to decrease by over two orders of magnitude as the charge was decreased from 0 to -12 , while the $K_{\mathrm{d}}$ value for the $\mathrm{Cu}^{\mathrm{II}}$ species with the same modifications only showed a modest decrease in affinity. These values were then used to calculate the reduction potentials, using the Nernst equation, and plotted as a function of the charge difference from the parent TRI-H (Figure $8 \mathrm{~A}$ ) at two specified $\mathrm{pH}$ values. These values
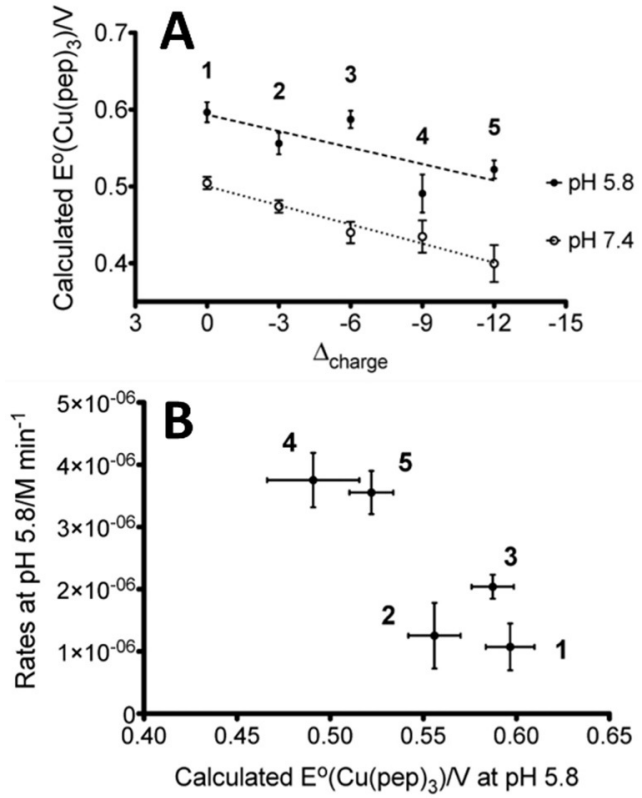

Figure 8. A) Calculated reduction potentials in relation to the changes in the local charge at $\mathrm{pH} 5.8$ and $\mathrm{pH}$ 7.4. B) Rates of NiR activity versus calculated reduction potentials at $\mathrm{pH}$ 5.8. Peptides: 1) TRIEHE27K, 2) TRI-EHE27Q, 3) TRI-EH, 4) TRI-EHK24Q, 5) TRI-EHK24E. Reprinted and adapted from Ref. [50] with permission. Copyright 2013 American Chemical Society.

also show a linear decrease as a function of increasing negative charge at both $\mathrm{pH} 5.8$ and 7.5 with a slope of $100 \mathrm{mV}$ per $1.6 \mathrm{pH}$ units, which is consistent with one proton per electron. This decrease in the calculated reduction potential is more reflective of the destabilization of the cuprous species in a more negatively charged environment than the stabilization of the cupric form, thereby resulting in a less positive reduction potential. The differences in the affinities of the cupric and cuprous forms of each model are separated by approximately $100 \mathrm{mV}$, with the more acidic $\mathrm{pH}$ values giving the more positive reduction potentials.

We had originally designed the series of outer-sphere $\mathrm{CuNiR}$ models with increasing negative charge to stabilize the more positively charged $\mathrm{Cu}^{\mathrm{II}}$ species, which would, in turn, decrease the reduction potentials. Although we did indeed observe the expected decrease in the reduction potential across the series, it was due to the destabilization of the $\mathrm{Cu}^{\mathrm{I}}$ species rather than the stabilization of the $\mathrm{Cu}^{\mathrm{II}}$ species. Thus, the finding that the $\mathrm{Cu}^{\mathrm{I}}$ affinity increased going from a more negative to a more positively charged metal binding environment suggested the involvement of hydrogen bonding and salt-bridging interactions. We proposed a rack-induced binding environment, similar to that suggested for blue copper electron-transfer proteins. ${ }^{[51]}$ In this model, the protein matrix constrains the metal coordination environment, thereby leading to changes in the stability of the different oxidation states, which are exploited to tune the redox potential of the copper center. Our results suggest that, in our model $\mathrm{CuNiR}$, this induced-rack effect is greater for the $\mathrm{Cu}^{\mathrm{I}}$ oxidation state. We proposed a hydrogen-bonding interaction between Glu 22 and His 23 that orients the imidazole ligand is responsible.

Finally, we examined the series of models with outersphere modifications for $\mathrm{CuNiR}$ rates, using the ascorbate assay described above. As the charge was decreased from 0 to -12 , we observed a fourfold increase across the series in NiR activity and a correlation with the reduction potential (Figure $8 \mathrm{~B}$ ). At $\mathrm{pH} 5.8$, the higher the reduction potential of our outer-sphere models, the lower the rate. Although this appears to show a linear trend linking the rate to the reduction potential, the assay conditions, in which ascorbate is added in significant excess, invalidate the conclusion that this is due to electron-transfer rates, as we have shown that the reduction of $\mathrm{Cu}^{\mathrm{II}}$ to $\mathrm{Cu}^{\mathrm{I}}$ by ascorbate is not rate-limiting. Instead, we suggest that the reorganization energy upon oxidation (from trigonal $\mathrm{Cu}^{\mathrm{I}}$ to pseudo-tetrahedral $\mathrm{Cu}^{\mathrm{II}}$ ) limits the observed rate. This study established that changes in the charge environment around the active site, through residue substitutions at positions nearby, can be used to modify properties that influence reduction potentials and NiR activities in a systematic fashion.

\subsection{Modification of the Steric Bulk and Addition of Potential Hydrogen-Bonding Residues in the Inner Sphere}

Having established the influence of outer-sphere modifications on CuNiR activity, we then turned to examining the role of inner-sphere modifications. It is well-known that innersphere residues of an enzyme play significant roles in catalysis, and mutations of inner-sphere residues have been shown to significantly alter catalytic rates and efficiencies. Therefore, using our rational design strategy, we identified two positions in the 3SCC where substitution of the Leu layer by other residues (Figure 6B) could lead to modification of the coordination environment of the bound $\mathrm{Cu}$ or $\mathrm{Cu}$ coordinated water molecule(s). We had previously shown that we could control the coordination number of $\mathrm{Cd}$ bound to tris(cysteine) sites by modifying the steric bulk of the hydrophobic layer spacing in the core above or below the $\mathrm{Cd}\left(\mathrm{S}_{3}\right)$ binding site. ${ }^{[16,52]}$ Thus, by modification of the steric bulk around a catalytically active metal binding site, we should be able to tune the substrate and solvent access.

By using this approach with our $\mathrm{Cu}\left(\mathrm{His}_{3}\right) \mathrm{NiR}$ site, we substituted leucine residues in positions 19 and 26, the leucine layers directly above and below the $\mathrm{Cu}(\mathrm{NiR})$ site (Table 4 and Figure $6 \mathrm{~B}){ }^{[53]} \mathrm{We}$ increased the steric bulk above the $\mathrm{Cu}$ binding site by substitution with isoleucine or D-leucine, as our first-generation CuNiR model was thought to be five- 
coordinate in the cupric state (compared to four-coordinate for native $\mathrm{CuNiR}$ ), and we believed that increasing the bulk above the metal binding site would decrease solvent access and lower the coordination number of the $\mathrm{Cu}$ center. We then tested the effect of decreased steric bulk above or below by substitution with alanine, as crystal structures of our heavymetal binding scaffolds have shown that decreased steric bulk can permit up to four additional water molecules. ${ }^{[34]}$ Finally, to study the effect of hydrogen bonding to the $\mathrm{Cu}$-coordinated water molecule(s) or histidine imidazole ligands and/or the addition of extra $\mathrm{Cu}$-coordinating residues, we made scaffolds that positioned aspartate above or below the copper site.

We examined this series of $\mathrm{CuNiR}$ models for $\mathrm{CuNiR}$ activity and observed rate constants that split the series into two identifiable groups (Figure 9, green bars)-those whose CuNiR initial rate constants were approximately the same as the parent TRI-H (L19I and L19 $\mathrm{D}$ ), and those whose CuNiR rate was between 60- to 75-fold greater (Ala and Asp substitutions). We believed that this trend in rate differences between the two groups was due to structural differences in the resting state of the $\mathrm{Cu}^{\mathrm{I}}$ forms, as we have shown that the reduction of the $\mathrm{Cu}^{\mathrm{II}}$ species is extremely rapid under our assay conditions. Therefore, we collected X-ray absorption data and compared the $1 \mathrm{~s} \rightarrow 4 \mathrm{p}$ energies in the XANES region (Figure 10) as well as bond lengths from EXAFS data.

The increase in the intensity of the $\mathrm{Cu}^{\mathrm{I}}$ pre-edge, as well as increases in the copper-ligand bond lengths from EXAFS data upon decreasing the steric bulk around the binding site, suggests that rather than permitting extra coordinating ligands to bind to the copper site, the reduction in the steric bulk allows the $\mathrm{Cu}^{\mathrm{I}}$ state to relax and reduce the coordination number from 3 to 2. This was the opposite of what we had observed when we modified the steric bulk surrounding heavy-metal binding sites, where decreased steric bulk led to an increase in the coordination number. We observed that the

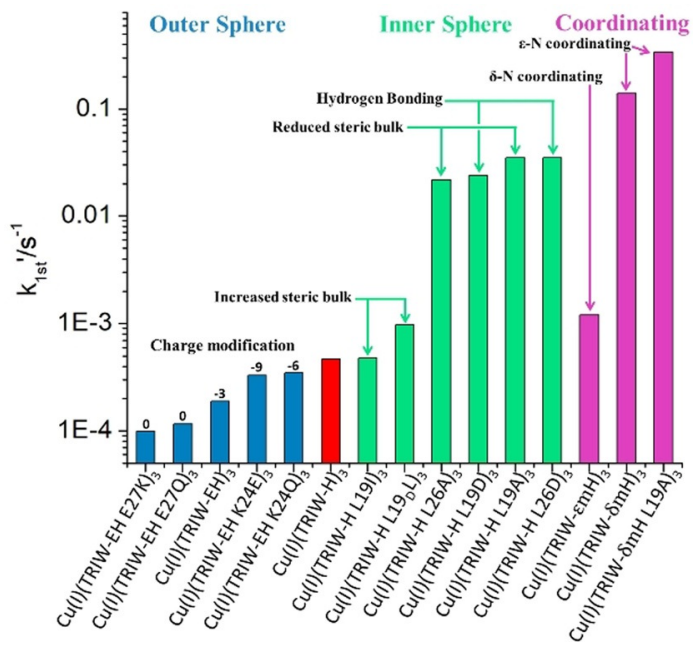

Figure 9. Pseudo-first-order rate constants of the original TRIW-H construct (red) reported in Ref. [37] compared to the outer-sphere helical interface residues (blue) reported in Ref. [50], interior residues (green) reported in Ref. [53], and primary coordinating residues (magenta) reported in Ref. [56]. Reprinted and adapted from Ref. [56] with permission. Copyright 2019 American Chemical Society.

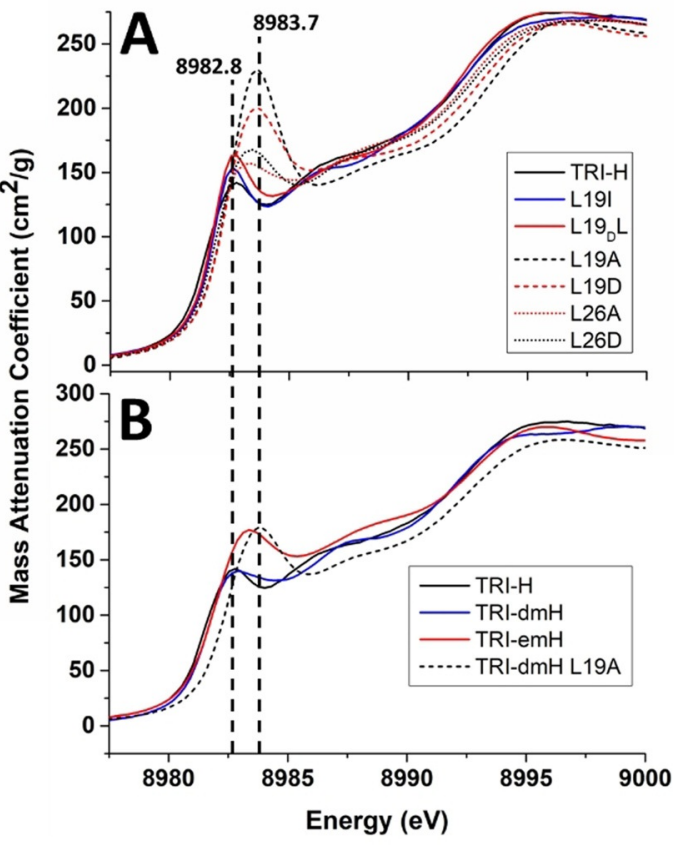

Figure 10. $\mathrm{Cu}^{\prime} \mathrm{XANES}$ at $\mathrm{pH} 5.8$ of $\mathrm{A}$ ) inner-sphere modifications and B) primary coordinating modifications compared to that of TRIW-H. Adapted and reprinted from Refs. [53] and [56] with permission. Copyright 2018 Wiley-VCH and 2019 American Chemical Society.

XANES $1 \mathrm{~s} \rightarrow 4 \mathrm{p}$ energies could accurately define the two groups, with the more active constructs showing a shift to higher energy compared to the parent TRI-H, and those whose rates were approximately the same and also had similar $1 s \rightarrow 4 p$ energies. This energy shift, which provides information on the electron density around the copper site and thus its ability to participate in redox chemistry, appears to correlate with the increase in the NiR activity, and would also have an impact on the potential energy landscape of the transition state during catalysis (see Section 3.2). Native CuNiRs have a four-coordinate $\mathrm{Cu}(\mathrm{His})_{3}\left(\mathrm{H}_{2} \mathrm{O}\right)$ in both the oxidized and reduced states, thus suggesting that the reorganization of our model copper binding sites may be a limiting factor in our activity enhancements.

\subsection{Role of Histidine Coordination Isomers in CuNiR Activity}

Another significant feature of imidazole moieties is the potential for either of the imidazole nitrogen atoms to be the coordinating ligand. As already mentioned in our discussion on PHM and CuNiR, these two enzymes display vastly different copper chemistry, but possess the same $\mathrm{Cu}$ (His) 3 copper environment. Close inspection of the structures of CuNiR (PDB: 4YSE ${ }^{[54]}$ ) and PHM (PDB: $1 \mathrm{PHM}^{[55]}$ ) reveals different tautomeric coordinative isomers, with the former coordinating copper through the $\mathrm{N}_{\varepsilon}$ atom and the later through the $\mathrm{N}_{\delta}$ atom of the imidazole. The difference in coordination $\left(\mathrm{N}_{\varepsilon}\right.$ versus $\left.\mathrm{N}_{\delta}\right)$ has been shown to be common in type $1 \mathrm{Cu}$ sites showing electron-transfer versus catalytic type $2 \mathrm{Cu}$ sites. To determine the orientation of the histidine 
coordination in our CuNiR model (TRI-H), we designed scaffolds that included $\mathrm{N}$-methylated histidine as the primary coordinating ligands (sequences in Table 4) ${ }^{[56]}$ Thus, we could compare $N_{\varepsilon}$-methylhistidine (TRI- ${ }_{\mathrm{em}} \mathrm{H}$, coordinating through $\mathrm{N}_{\delta}$ ) with $N_{\delta}$-methylhistidine (TRI- ${ }_{\delta \mathrm{m}} \mathrm{H}$, coordinating through $\mathrm{N} \varepsilon$ ) to our original design and elucidate not only the coordination state, but also the effect of forcing the flipped coordination mode, thereby determining directly the influence of copper-histidine coordination isomers on properties of our well-understood metalloezymatic system.

It is important to note here that methylation of the imidazole fundamentally alters the properties of the ligand, not limited to only the N-coordination. The replacement of one of the $\mathrm{N}-\mathrm{H}$ moieties by $\mathrm{N}-\mathrm{Me}$ removes an opportunity for hydrogen bonding and changes the $\mathrm{p} K_{\mathrm{a}}$ value and accessible charge of the ligand. Furthermore, the methyl group is a much stronger electron donor, changing the electronic nature of the imidazole ligand, often in ways that are difficult to predict. ${ }^{[57]}$ Finally, $N$-methylimidazoles are much more sterically demanding than the parent histidine groups, which could have a significant impact on the geometry and stability of our $\mathrm{Cu}$ sites. Thus, there are numerous factors that have to be taken into account when considering substitution with $N$-methylhistidine.

We characterized the effect on forced $\varepsilon$ - or $\delta$-nitrogen coordination (by methylation of the other imidazole nitrogen atom) on the geometry, redox potential, and catalytic activity of the copper binding site. EPR, XAS, and UV/Vis spectroscopic data suggested that TRI- ${ }_{\varepsilon m} \mathrm{H}$ has a lower number of coordinating imidazole ligands than TRI- ${ }_{\delta \mathrm{m}} \mathrm{H}$ for both the $\mathrm{Cu}^{\mathrm{I}}$ and $\mathrm{Cu}^{\mathrm{II}}$ states (Figure 11). Significantly, TRI- ${ }_{\delta \mathrm{m}} \mathrm{H}$ more closely mimicked the geometric features of the original TRI-H, with TRI- ${ }_{\varepsilon m} \mathrm{H}$ showing more of a tetrahedral nature for the $\mathrm{Cu}^{\mathrm{II}}$ species $\left(\mathrm{N}_{3} \mathrm{O}\right.$ versus $\mathrm{N}_{2} \mathrm{O}_{2}$ coordination environment for TRI-H and TRI- ${ }_{\delta \mathrm{m}} \mathrm{H}$ ) and more two-coordinate character for the $\mathrm{Cu}^{\mathrm{I}}$ species in contrast to the threecoordinate character of the other two. These data suggest that the parent TRI-H coordinates with the $\varepsilon$-nitrogen atom. As with our inner-sphere modifications, we observed a shift in

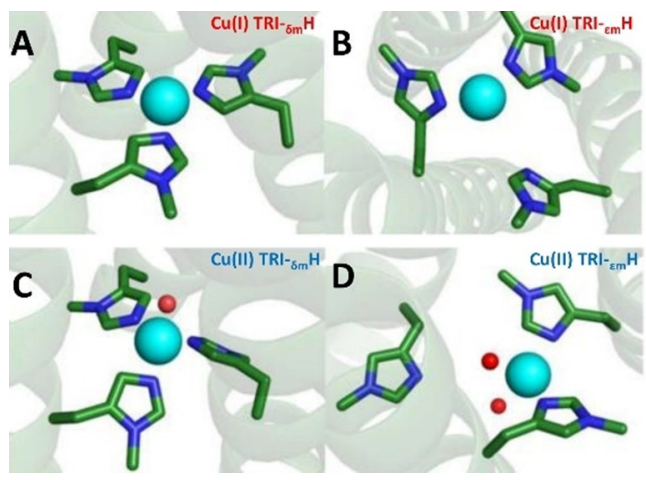

Figure 11. Models of the metal binding sites of A) Cu'-TRIW- $\delta m H$ and B) Cu'-TRIW- $\varepsilon m H$, C) Cu"-TRIW- $\delta m H$, and D) Cu"-TRIW- $\varepsilon m H$. Models were made using the program PyMol and based on the $\mathrm{Zn}^{\prime \prime}(\mathrm{His})_{3}$ site of $\mathrm{Hg}^{11}{ }_{\mathrm{S}} \mathrm{Zn}_{\mathrm{N}}(\mathrm{CSL} 9 \mathrm{CL} 23 \mathrm{H})_{3}$ [PDB: 3PBJ ${ }^{[12]}$. Reprinted and adapted from Ref.[56] with permission. Copyright 2019 American Chemical Society. the $1 \mathrm{~s} \rightarrow 4 \mathrm{p}$ energy in the XANES region, with TRI- ${ }_{\delta \mathrm{m}} \mathrm{H}$ matching the energy of the parent, whereas $\mathrm{TRI}-{ }_{\varepsilon m} \mathrm{H}$ is slightly higher in energy (Figure 10B).

Finally, we compared the NiR activity of the $N$-methylhistidine-containing scaffolds to our previous designs (Figure 9, magenta). We observed the largest increase in NiR activity through modification of the primary coordinating ligands. Interestingly, the largest enhancement in rate came from methylation of the $\delta$-nitrogen atom, which forced $\varepsilon$-nitrogen coordination, the same as in TRI-H. We concluded that an inductive-like effect upon $\mathrm{N}$-alkylation, linked to increases in the HOMO energy from more electron-rich ligands, accounted for the difference between the two scaffolds. We attempted to combine the features that generated the best NiR activities from the previous inner-sphere modifications (reduction of steric bulk through L19A mutation, 75-fold increase in rate compared to TRI-H) with the best primary coordinating substitution $\left(\mathrm{TRI}_{-{ }_{\delta m}} \mathrm{H}, 260\right.$-fold rate enhancement) to give TRI- ${ }_{\delta m} \mathrm{H}$ L19A. Although this only resulted in a modest 2.5-fold increase in rate versus that of the TRI- ${ }_{\delta m} \mathrm{H}$, this scaffold is the best $\mathrm{CuNiR}$ model to date in a homogeneous aqueous system, with a 640-fold rate enhancement compared to our first generation CuNiR, TRI-H. Although this is currently the best synthetic homogeneous copper catalyst for CuNiR activity, the rate is 400000 fold lower than the native system.

Michaelis-Menten kinetics analysis of the CuNiR activities of our models revealed that this decreased activity is due to factors that impact both the maximal catalytic rate as well as substrate access and binding (Table 5). The $V_{\max }$ value plateaus, while the biggest influence on catalytic efficiency arises from $K_{\mathrm{M}}$ effects. Again, we have thus far not included the critical acid-base catalyst, an aspartate that is important in the activity of the native protein, in our CuNiR models. We have already attempted to add a nearby Asp residue, but the enforced threefold symmetry meant that three Asp residues were positioned near the $\mathrm{CuHis}_{3}$ site, and we believe that those aspartate residues interacted with each other rather than with the $\mathrm{Cu}$ site. ${ }^{[53]}$ Additionally, we observed a significantly decreased $K_{\mathrm{M}}$ value compared to small-molecule models, which suggests that substrate recognition and access is limited in our scaffold design. This difference may also reflect $\mathrm{NO}_{2}{ }^{-}$binding to $\mathrm{Cu}^{\mathrm{I}}$ over $\mathrm{Cu}^{\mathrm{II}}$ and suggests we need to make future alterations that enhance substrate binding, such as new scaffolds that will allow for asymmetric modification of the scaffold. We have developed such a scaffold, which will be described soon. ${ }^{[63]}$

\section{Design of Electron-Transfer Sites in De Novo Scaffolds}

We now turn to the discussion of our recent developments in the de novo design of electron-transfer sites in our alphahelical scaffold systems. Metal binding sites that transfer electrons across membranes, between metal binding sites, or coupled to proton transfers require metal binding sites that can support the different geometric and ligand preferences of the different redox states, as is the case for metal binding sites 
Table 5: Kinetic parameters for CuNiR activity for select 3SCCs and small-molecule model complexes at $\mathrm{pH} 5.8$.

\begin{tabular}{|c|c|c|c|c|c|}
\hline Construct & $\operatorname{Rate}^{[\mathrm{a}]}\left[\mathrm{s}^{-1}\right]$ & $V_{\max }\left[\mathrm{M} \mathrm{s}^{-1}\right]$ & $K_{\mathrm{M}}[\mathrm{M}]$ & $k_{\text {cat }}\left[\mathrm{s}^{-1}\right]$ & $k_{\text {cat }} / K_{\mathrm{M}}\left[\mathrm{s}^{-1} \mathrm{M}^{-1}\right]$ \\
\hline TRIW-H $\mathrm{H}^{[58]}$ & $4.6 \times 10^{-4}$ & $\mathrm{~N} / \mathrm{A}$ & $\mathrm{N} / \mathrm{A}$ & $\mathrm{N} / \mathrm{A}$ & $\mathrm{N} / \mathrm{A}$ \\
\hline TRIW-H L19A ${ }^{[59]}$ & $3.5 \times 10^{-2}$ & $2.3 \pm 0.3 \times 10^{-6}$ & $0.24 \pm 0.05$ & $0.23 \pm 0.03$ & $1.0 \pm 0.3$ \\
\hline TRIW- ${ }_{-m} \mathrm{H}$ & 0.12 & $1.5 \pm 0.1 \times 10^{-5}$ & $0.18 \pm 0.02$ & $1.5 \pm 0.1$ & $8.2 \pm 0.1$ \\
\hline TRIW- ${ }_{\delta m} \mathrm{H}$ L19A & 0.30 & $1.5 \pm 0.1 \times 10^{-5}$ & $0.13 \pm 0.01$ & $1.5 \pm 0.1$ & $11.3 \pm 0.1$ \\
\hline TRIW- ${ }_{\varepsilon m} \mathrm{H}$ & $1.2 \times 10^{-3}$ & $\mathrm{~N} / \mathrm{A}$ & $\mathrm{N} / \mathrm{A}$ & $\mathrm{N} / \mathrm{A}$ & $\mathrm{N} / \mathrm{A}$ \\
\hline$\left[\mathrm{CuMe}_{2} \mathrm{bpa}\left(\mathrm{H}_{2} \mathrm{O}\right)\left(\mathrm{ClO}_{4}\right)\right]^{+}$on electrode $\mathrm{pH} \mathrm{5.5^{[60] }}$ & $\mathrm{N} / \mathrm{A}$ & $\mathrm{N} / \mathrm{A}$ & $1.1 \times 10^{-3}$ & 0.063 & 57.3 \\
\hline$\left[\mathrm{CuMe}_{2} \mathrm{bpa}\left(\mathrm{H}_{2} \mathrm{O}\right)\left(\mathrm{ClO}_{4}\right)\right]^{+}$in solution $\mathrm{pH} 5.5^{[60]}$ & $\mathrm{N} / \mathrm{A}$ & $\mathrm{N} / \mathrm{A}$ & $2.5 \times 10^{-3}$ & $5.3 \times 10^{-5}$ & 0.02 \\
\hline AfCuNiR pH $6.5^{[61]}$ & $\mathrm{N} / \mathrm{A}$ & $\mathrm{N} / \mathrm{A}$ & $1.5 \times 10^{-4}$ & 620 & $4.1 \times 10^{6}$ \\
\hline AxCuNiR pH $7.0,4{ }^{\circ} \mathrm{C}^{[62]}$ & $\mathrm{N} / \mathrm{A}$ & $\mathrm{N} / \mathrm{A}$ & $2.7 \times 10^{-3}$ & 89 & $3.3 \times 10^{5}$ \\
\hline
\end{tabular}

[a] The value of the rate constant refers to the pseudo-first-order rate constant for the metallopeptide-catalyzed reduction of nitrite by ascorbate in solutions containing $30 \mathrm{~mm}$ nitrite and $1.2 \mathrm{~mm}$ ascorbate. $\mathrm{N} / \mathrm{A}=$ not determined/not available. ${ }^{[58]}$

involved in redox cycling in a catalytic site, such as CuNiR. As discussed in more detail above, this requires careful consideration of the coordination number and geometry as well as ligand positioning within the scaffold. We will highlight the development of our models for iron-containing rubredoxins and copper-containing cupredoxins.

\subsection{Development of Non-Heme Iron Rubredoxin Models}

FeS cluster proteins are a class of proteins with cofactors of varying complexity ranging from a single $\mathrm{Fe}$ atom bound by four cysteine residues (ex. rubredoxin) ${ }^{[64]}$ to multiatom cofactors that must be assembled by separate protein machinery before being inserted into the final target protein (ex. the P cluster of nitrogenase). ${ }^{[65]}$ The relative simplicity of rubredoxin and the extensive literature available on its geometry and spectroscopic properties make an attractive target for metalloprotein design. ${ }^{[3 \mathrm{~b}]}$

Previous attempts to design rubredoxin focused on replicating the hairpin of the native binding site to show that the same secondary structure and metal binding site could be created using a de novo protein sequence. ${ }^{[6]}$ The Regan group used the program Metal Search to put a tetrahedral $\mathrm{Cys}_{4}$ site into the B1 domain of IgG-binding protein $\mathrm{G}$, but although this construct was able to recapitulate the $\mathrm{Fe}^{\mathrm{III}}$ spectroscopic properties of rubredoxin it was not a functional redox center. ${ }^{[66 \mathrm{~d}]}$ The DeGrado group. created a rubredoxin mimic by recapitulating the local secondary geometry around the $\mathrm{Fe}$ in the native protein and minimizing the surrounding protein needed to maintain this geometry to a 40 amino acid peptide. ${ }^{[666]}$ This construct not only successfully mimicked the $\mathrm{Fe}^{\mathrm{III}}$ spectroscopic properties of native rubredoxin, but was the first de novo rubredoxin mimic capable of reliable redox cycling up to 16 cycles. Arguably the most successful simplification of rubredoxin was created by the Sénèque group within a 18 amino acid peptide composed of a cyclic portion and a linear tail. ${ }^{[66]}$ Although this construct was capable of less redox cycles than the model developed by the DeGrado group (7 compared to 16), it successfully recreated the $\mathrm{Fe}^{\mathrm{II}}$ and $\mathrm{Fe}^{\mathrm{III}}$ spectroscopic properties of native rubredoxin with less than half of the amino acids.

We focused our efforts on determining whether this hairpin turn secondary structure was necessary to recapitulate the spectroscopic properties of a rubredoxin by implanting a rubredoxin-type $\mathrm{Cys}_{4}$ binding site within an alpha-helical bundle (Figure 12). ${ }^{[67]}$ Our group had previously designed two $\mathrm{Cys}_{4}$ proteins based on the heavy-metal binding $\mathrm{Cys}_{3}$ peptide $\alpha_{3}$ DIV $\left(\alpha_{3}\right.$ DIV H72C or L21C) as models for the Cd binding site of $\mathrm{CadC}^{[68]}$ By using ${ }^{113} \mathrm{Cd}$ NMR spectroscopy we determined that the $\mathrm{H} 72 \mathrm{C}$ variant, which positioned the fourth Cys in a nearby loop region, formed $\mathrm{CdS}_{3} \mathrm{O}$ while L21C, which positioned the fourth Cys as part of a CXXC chelate motif, formed $\mathrm{CdS}_{4}$. We tested both $\alpha_{3}$ DIV H72C and L21C as prospective rubredoxin models.

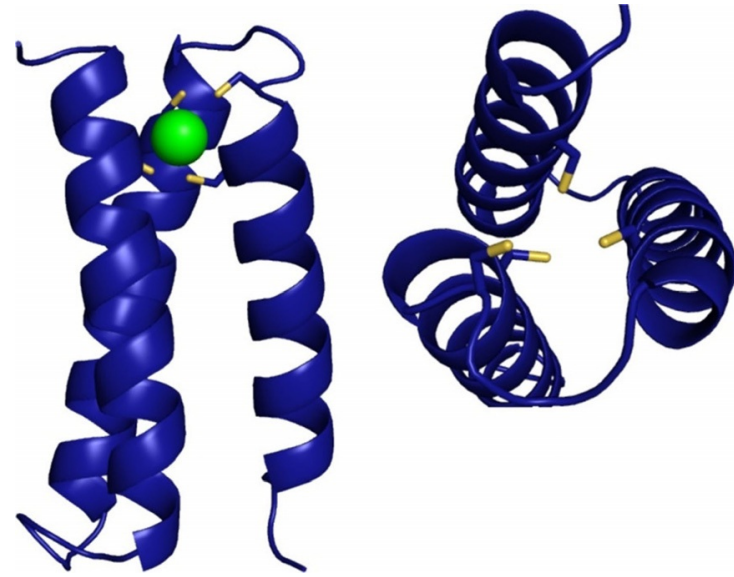

Figure 12. Model of the synthetic rubredoxin, Fe- $\alpha 3$ DIV L21C, constructed in PyMol based on the NMR structure of $\alpha 3$ DIV (PDB: 2MTQ). Reproduced from Ref. [67] with permission. Copyright 2018 American Chemical Society.

When expressing $\alpha_{3}$ DIV H72C and L21C in media containing supplemental $\mathrm{Fe}$, the lysate of the $\mathrm{L} 21 \mathrm{C}$ variant was red in color, thus indicating some level of $\mathrm{Fe}$ incorporation in vivo. Similar expressions of either $\alpha_{3}$ DIV alone or its $\mathrm{H} 72 \mathrm{C}$ variant gave a standard yellowish color. Hence, our characterization efforts focused on $\alpha_{3}$ DIV L21C as a possible rubredoxin mimic using UV/Vis, Mössbauer, EPR, magnetic circular dichroism (MCD), and X-ray absorption spectroscopy. Purified peptide was reconstituted with $\mathrm{Fe}$ by the addition of $\mathrm{Fe}^{\mathrm{II}}$ before oxidizing in air to produce the $\mathrm{Fe}^{\mathrm{III}}$ form. The optical absorption spectra of $\mathrm{Fe}^{\mathrm{III}}-\alpha_{3}$ DIVL21C showed 
Table 6: Physical properties of constructs reported in Ref. [67].

\begin{tabular}{|c|c|c|c|c|}
\hline Protein & $\begin{array}{l}\text { UV/Vis: } \lambda[\mathrm{nm}] \\
\left(\varepsilon\left[\mathrm{M}^{-1} \mathrm{~cm}^{-1}\right]\right.\end{array}$ & $\begin{array}{l}\text { Redox potential (vs. } \\
\mathrm{NHE} \text { [ }[\mathrm{mV}]\end{array}$ & $\begin{array}{l}\mathrm{Fe}^{\prime \prime \prime} \text { Mössbauer }\left(\delta \text { and } \Delta E Q\left[\mathrm{~mm} \mathrm{~s}^{-1}\right], D\right. \\
\left.\left[\mathrm{cm}^{-1}\right], A[T]\right)\end{array}$ & $\begin{array}{l}\mathrm{Fe}^{\prime \prime} \text { Mössbauer }\left(\delta \text { and } \Delta E Q\left[\mathrm{~mm} \mathrm{~s}^{-1}\right] \text {, }\right. \\
\left.D\left[\mathrm{~cm}^{-1}\right], A[T]\right)\end{array}$ \\
\hline \multirow[t]{4}{*}{ rubredoxin $^{[69,70]}$} & $750(350)$ & -90 to +50 & $\delta / \triangle E Q=0.24 /-0.5, \eta=0.2$ & $\delta / \Delta E Q=0.70 /-3.25, \eta=0.65$ \\
\hline & $570(3200)$ & & $D=+1.9, E / D=0.23$ & $D=+7.4, E / D=0.28$ \\
\hline & $490(6600)$ & & $A_{x x, y y, z z}=(-16,-15.9,-16.9)$ & $A_{x x, y y, z z}=(-20.1,-8.3,-30.1)$ \\
\hline & $370(7710)$ & & & \\
\hline \multirow[t]{3}{*}{$\alpha_{3}$ DIV L21C } & $595(1200)$ & $-75(\mathrm{pH} 8.5)$ & $\delta / \Delta E Q=0.26 /-0.5, \eta=0.0$ & $\delta / \Delta E Q=0.73 /-3.40, \eta=0.9$ \\
\hline & $491(2700)$ & & $\mathrm{D}=+0.5, E / D=0.15$ & $D=+7, E / D=0.26$ \\
\hline & $345(5000)$ & & $A_{x x, y y, z z}=(-15.9,-16,-17)$ & $A_{x x, y y, z z}=(-16,-7.3,-25)$ \\
\hline
\end{tabular}

ligand-metal charge-transfer (LMCT) bands at similar energies as native rubredoxin (Table 6), but with about $30 \%$ of the expected intensity, consistent with other spectroscopic data, which would indicate some proportion of contaminant within the construct (see below). ${ }^{[69]}$

MCD analysis enabled the optical spectrum of $\mathrm{Fe}^{\mathrm{III}}$ $\alpha_{3}$ DIV L21C to be deconvoluted to nine unique peaks that matched in energy to those seen in native rubredoxin. Further investigation of the optical spectrum through MCD at variable temperatures and variable fields determined the saturation behavior to be consistent with that of native rubredoxin. Mössbauer spectra of $\mathrm{Fe}^{\mathrm{II}}-\alpha_{3} \mathrm{DIV}$ L21C recorded at $4.2 \mathrm{~K}$ were consistent with those of native rubredoxin, but high-field spectra revealed two unique components: $60 \%$ $\mathrm{FeS}_{4}$ and $40 \% \mathrm{FeS}_{3} \mathrm{O} .{ }^{[70 \mathrm{a}]}$ The Mössbauer results of $\mathrm{Fe}^{\mathrm{III}}$ $\alpha_{3}$ DIV L21C were similar, with the bulk of the sample showing similar spectra as rubredoxin but $25 \%$ of the sample was concluded to be impurities of ferric oxides/ hydroxides. This impurity was also observed in the X-band EPR spectrum, although it was largely consistent with native rubredoxin. Lastly, EXAFS analysis revealed that $\mathrm{Fe}^{\mathrm{II}}$ $\alpha_{3}$ DIVL21C was dominated by a single distance $\mathrm{Fe}-\mathrm{S}$ scatterer bond distance of $2.32 \AA$.

We analyzed the electrochemistry of $\mathrm{Fe}^{\mathrm{II}} / \mathrm{Fe}^{\mathrm{III}}$ $\alpha_{3}$ DIV L21C to investigate its activity as an electron-transfer site and determined a one-electron transfer with a potential of $-75 \mathrm{mV}$, which falls within the -90 to $50 \mathrm{mV}$ range seen in native rubredoxins. ${ }^{[64 a, f, 70 b, 71]} \mathrm{pH}$-dependent studies of the redox potential found it was a coupled 2-proton-1-electron event. This differs from native rubredoxins whose redox potentials are independent of the $\mathrm{pH}$ value. We hypothesize that charged residues near the metal binding site of our construct may be the cause of this effect. Chemical reduction with dithionite followed by oxidation in air could be cycled up to three times before the construct was irreversibly bleached, likely caused by the oxidation of cysteine.

This characterization effort was the most robust ever undertaken for a designed rubredoxin and showed that one can construct a tetrahedral $\mathrm{FeS}_{4}$ center within a rigid scaffold unrelated to the native secondary structure. We also determined that the CXXC motif of native rubredoxins is an important part of maintaining this metal binding geometry within a protein, as our scaffold without this motif was unable to recapitulate the spectroscopic properties of a tetrahedral $\mathrm{FeS}_{4}$. Comparison of the MCD data with the results from the Mössbauer and EPR studies showed that our construct also reaffirms the $D$-sign controversy seen in native rubredoxins, in which MCD favors a negative value while Mössbauer and EPR favor a positive value. ${ }^{[70 a, 72]}$ Moving forward, high-field EPR spectroscopy and further protein design of this construct should be used to investigate this apparent disagreement.

\subsection{Development of Cupredoxin Models}

Type $1 \mathrm{Cu}$ proteins are electron-transfer proteins with a Greek key beta barrel fold and a $\mathrm{CuHis}_{2} \mathrm{CysXxx}$ binding site, in which Xxx can vary between Met, Gln, and (in one instance) Glu. These proteins have long fascinated the bioinorganic community because of their constrained geometry, unique optical properties that lead to bright blue, green, or red solutions, and compressed hyperfine coupling constants in their EPR spectra. ${ }^{[73]}$ Blue type $1 \mathrm{Cu}$ proteins have an intensive LMCT band at $600 \mathrm{~nm}$ which is assigned as a Cys$\mathrm{Cu} \pi-\mathrm{d}_{\mathrm{x}^{2}-\mathrm{y}^{2}}$ transition, a short $\mathrm{Cu}-\mathrm{Cys}$ bond of 2.1-2.2 $\AA$, and compressed hyperfine coupling constants $\mathrm{A}_{\|}$below $100 \times$ $10^{-4} \mathrm{~cm}^{-1} \cdot{ }^{[74}$ Green type $1 \mathrm{Cu}$ proteins have an additional LMCT band at $450 \mathrm{~nm}$, which is assigned as a Cys-Cu $\sigma-\mathrm{d}_{\mathrm{x}^{2}-\mathrm{y}^{2}}$ transition, with a ratio between the two intensities of around one, a slightly longer $\mathrm{Cu}-\mathrm{Cys}$ bond of $2.2 \AA$, and similarly compressed hyperfine coupling constants $\mathrm{A}_{\|} \cdot{ }^{[75]}$ Finally, red type $1 \mathrm{Cu}$ proteins have a much more intense $\sigma$-LMCT band at $390 \mathrm{~nm}$, a blue-shifted and diminished Cys- $\mathrm{Cu} \pi-\mathrm{d}_{\mathrm{x}^{2}-\mathrm{y}^{2}}$ transition at $500 \mathrm{~nm}$ with a $\varepsilon_{\sigma /} \pi$ ratio of about 3 , an EPR spectrum similar to that of type $2 \mathrm{Cu}$ proteins, and $\mathrm{Cu}-\mathrm{Cys}$ bonds closer to $2.3 \AA{ }^{[76]}$

Previous efforts to design type $1 \mathrm{Cu}$ proteins in scaffolds unrelated to the native structures have largely produced green copper proteins. ${ }^{[7]}$ The Valentine group showed that they could recreate the spectroscopic properties of a green copper protein with a $\mathrm{H} 80 \mathrm{C}$ variant of $\mathrm{Cu} / \mathrm{Zn}$ superoxide dismutase, while Hellinga created a series of thioredoxin variants capable of recreating the spectroscopic properties of green copper proteins upon the addition of the exogenous ligand azide. ${ }^{[77 a, b]}$ By using a combinatorial approach, the Hildebrandt group created and screened 180 different $\mathrm{His}_{2}$ Cys motifs containing four helical bundle peptides and found several that had the characteristic spectroscopic properties of green copper proteins. ${ }^{[77 c]}$ The most successful studies towards a de novo blue copper protein were those of the Tanaka group, who modified a previous $\mathrm{His}_{2} \mathrm{Glu} \mathrm{Cu}$ binding protein within a four helical bundle scaffold to make a $\mathrm{His}_{2} \mathrm{Cys}$ binding site and successfully generated a green copper protein by rational design. ${ }^{[77 d]}$ Interestingly, the 
A

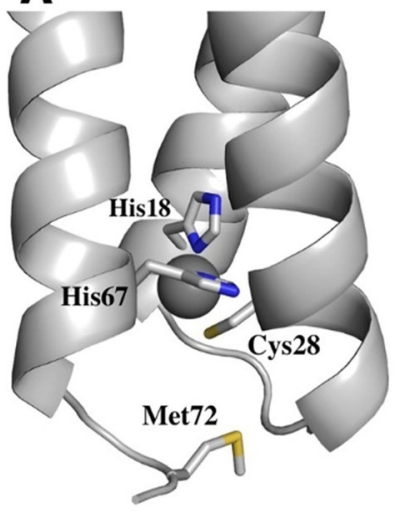

B

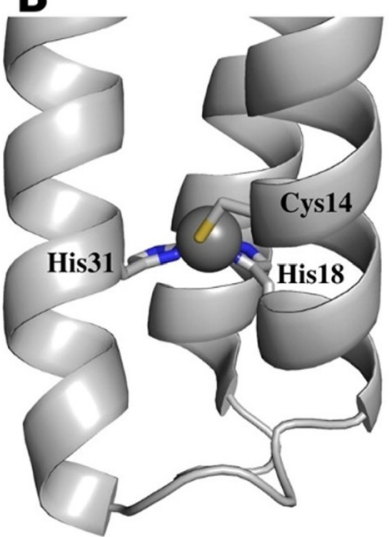

C

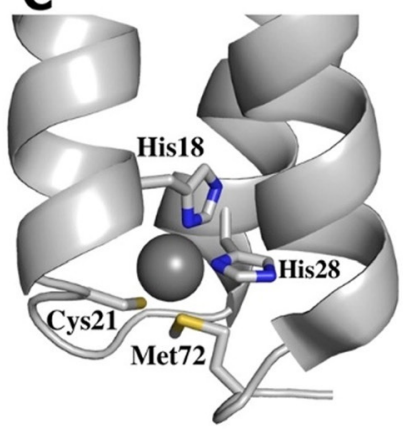

D

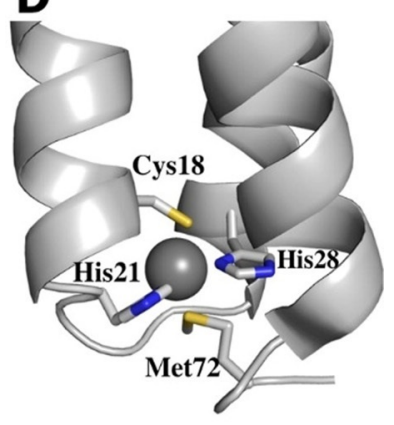

Figure 13. Models of the reduced state based on the EXAFS analysis of the designed cupredoxins. A) $\left.\left.C u^{\prime} \alpha_{3} D C R 1, B\right) C u^{\prime} \alpha_{3} D C h C 2, C\right) C u^{\prime} \alpha_{3} D C H 3$, D) $\mathrm{Cu}^{\prime} \alpha_{3} \mathrm{DCH} 4$. Reproduced from Ref. [79] with permission. Copyright 2015 American Chemical Society.

addition of several exogenous ligands such as chloride, sulfate, acetate, and phosphate were shown to tune this green copper into a blue copper spectroscopically. ${ }^{[78]}$ Although all these studies were impressive and pushed the field forward, the need for an exogenous ligand to recapitulate the spectroscopic properties of a blue copper protein meant that the question of how one could design a selfcontained blue copper protein in a de novo scaffold remained unanswered.

We had previously shown that a $\mathrm{His}_{3}$ or $\mathrm{Cys}_{3}$ metal binding site could be designed into the $3 \mathrm{HB}$ protein $\alpha_{3} \mathrm{D}$, but this was our first attempt at a mixed coordination sphere. ${ }^{[2480]}$ Four different prospective cupredoxins were designed into the $\alpha_{3} \mathrm{D}$ scaffold: $\mathrm{CR} 1, \mathrm{CH} 3, \mathrm{CH} 4$, and $\mathrm{ChC} 2$ (Figure 13 and Table 7). ${ }^{[79]} \alpha_{3}$ DCR1 incorporates a His2Cys binding site that spans the three helices at residues 18, 28, and 67 (the same positions previously used for $\alpha_{3}$ DIV and $\alpha_{3} \mathrm{DH} 3$ ) with a nearby Met residue at position 72. $\alpha_{3} \mathrm{DCH} 3$ and $\alpha_{3} \mathrm{DCH} 4$ were designed with chelate motifs of $\mathrm{CXXH}$ or $\mathrm{HXXC}$, respectively, on helix 1 , with the His and Met ligands divided between the two remaining helices. Lastly, the $\alpha_{3} \mathrm{DChC} 2$ design repositions the metal binding site of $\alpha_{3} \mathrm{DCH} 4$ further towards the $\mathrm{N}$-terminus of the peptide and the center of the hydrophobic core and encloses it within a "box" of hydrophobic residues in an attempt to enforce an entatic or rack state similar to native type $1 \mathrm{Cu}$ proteins.

Denaturation with $\mathrm{GuHCl}$ followed using circular dichroism spectroscopy showed that, with the exception of $\alpha_{3} \mathrm{DChC} 2$, all four constructs were alpha-helical and stably folded in solution. UV/Vis and EPR spectroscopic studies on the $\mathrm{Cu}^{\mathrm{II}}$ form were carried out to determine how well each construct had recapitulated the $\mathrm{Cu}^{\mathrm{II}}$ geometry of a type $1 \mathrm{Cu}$ protein. $\alpha_{3}$ DCR 1 exhibited spectra similar to those of a type 2 copper-thiolate species with a pronounced LMCT band at $380 \mathrm{~nm}$ and a shoulder at $550 \mathrm{~nm}$ with a $\varepsilon_{\sigma / \pi}$ ratio of 3.6 and a hyperfine coupling constant of $163 \times 10^{-4} \mathrm{~cm}^{-1} \cdot \alpha_{3} \mathrm{DCH} 3$ formed a yellow species with an intense band at $400 \mathrm{~nm}$ and a broad band between 600 and $800 \mathrm{~nm}$, which resulted in an extremely high $\varepsilon_{\sigma / \pi}$ of 11.9 and a hyperfine coupling constant of $152 \times 10^{-4} \mathrm{~cm}^{-1} . \alpha_{3} \mathrm{DCH} 4$ had absorption bands at 377,450 , and $520 \mathrm{~nm}$ with a $\varepsilon_{\sigma / \pi}$ ratio of 3.3 and a hyperfine coupling constant $\mathrm{A}_{\|}$of $185 \times 10^{-4} \mathrm{~cm}^{-1}$. Interestingly, a simple flip of a chelate motif from $\mathrm{CH} 3$ to $\mathrm{CH} 4$ had drastically changed the spectroscopic properties of the $\mathrm{Cu}^{\mathrm{II}}$ species. We hypothesized that this change was caused by the more buried position of the Cys metal binding site when this chelate motif was flipped. This led to the design of $\alpha_{3} \mathrm{DChC} 2$, in which this Cys residue is buried even further, and attempted to create a hydrophobic box around the bound $\mathrm{Cu}$ center. $\alpha_{3} \mathrm{DChC} 2$ has two intense bands at 401 and $499 \mathrm{~nm}$ with $\varepsilon_{\sigma / \pi}=2.2$ and a slightly compressed hyperfine coupling constant of $130 \times 10^{-4} \mathrm{~cm}^{1}$ resulting in a red-brown copper species. The optical properties of this construct is reminiscent of blue 
copper protein variants such as M121E azurin or M148E rusticyanin as well as the native red copper protein nitrosocyanin. ${ }^{[82-83]}$

One of the most striking results from this study was that all four constructs recapitulated the $\mathrm{Cu}^{\mathrm{I}}$ geometry of a blue copper protein regardless of how successful that construct was at recapitulating the $\mathrm{Cu}^{\mathrm{II}}$ geometry and spectroscopic properties. EXAFS data for the $\mathrm{Cu}^{\mathrm{I}}$ species of all four constructs showed short $\mathrm{Cu}-\mathrm{Cys}$ bond lengths between 2.18 and $2.22 \AA$ with long-distance scatterers observed from His ligation. Analysis of the $\mathrm{Cu}^{\mathrm{I}}$ XANES $1 \mathrm{~s} \rightarrow 4 \mathrm{p}$ transition at $8984 \mathrm{eV}$ of all four constructs divided the constructs into two groups: the copper centers in $\mathrm{ChC} 2$ and $\mathrm{CR} 1$ being more 3-coordinate, while those in $\mathrm{CH} 3$ and $\mathrm{CH} 4$ were more 4-coordinate. With potentials ranging between 364 and $462 \mathrm{mV}$, protein film voltammetry determined that all four constructs were also successful in modeling the redox potential of a blue copper protein, which typically range from 300 to $730 \mathrm{mV}^{[81 \mathrm{~b}, 83 \mathrm{~b}, 84]}$

These studies showed that the design of the cupredoxin site within a $3 \mathrm{HB}$ could have drastic effects on the spectroscopic properties of the bound $\mathrm{Cu}^{\mathrm{II}}$ ion. Our designs culminated in $\alpha_{3} \mathrm{DChC} 2$, which successfully recapitulated the spectroscopic properties of a red copper protein with a $\mathrm{Cu}^{\mathrm{I}}$ geometry and the redox potential of a blue copper protein. We postulated that a more complete understanding of the metal binding site created by $\alpha_{3} \mathrm{DChC} 2$ would allow us to tune the spectroscopic properties of this $\mathrm{Cu}^{\mathrm{II}}$ construct to those of a green or blue copper protein. That the $\mathrm{Cu}^{\mathrm{I}}$ geometry and redox potential of these constructs remained invariant across our designs indicates that if one were able to tune the spectroscopic properties of the $\mathrm{Cu}^{\mathrm{II}}$ form of the construct towards those of a blue copper protein, the other parameters would already be in place.

Our success with recapitulating a red copper protein with $\alpha_{3} \mathrm{DChC} 2$ lead us to revisit this construct to gain clues to how it might be tuned into models for green or blue copper proteins. One possibility was that the relative instability of $\alpha_{3} \mathrm{DChC} 2$, as determined by chem-

Table 8: Physical properties of constructs reported in Ref. [11].

\begin{tabular}{llll}
\hline Protein & $\begin{array}{l}\text { UV/Vis: } \lambda[\mathrm{nm}] \\
\left(\varepsilon\left[\mathrm{M}^{-1} \mathrm{~cm}^{-1}\right]\right)\end{array}$ & $\begin{array}{l}\text { EPR: } \\
\mathrm{A}_{\|} \times 10^{-4} \mathrm{~cm}^{-1}\end{array}$ & $\begin{array}{l}\text { Redox potential (vs. NHE) } \\
{[\mathrm{mV}]}\end{array}$ \\
\hline GRo ${ }_{3}$ DChC2 & $\begin{array}{l}400(3760), 490(1600) \\
\varepsilon_{\sigma / \pi}=2.3\end{array}$ & 142 & +530 \\
GRa3DChC2 R24A & $\begin{array}{l}399(2520), 490(1150) \\
\varepsilon_{\sigma / \pi}=2.2\end{array}$ & 142 & - \\
GRa3DChC2 & $\begin{array}{l}399(3480), 493(1450) \\
\varepsilon_{\sigma / \pi}=2.4\end{array}$ & 138 & - \\
R24M & & +510 \\
GRa3DChC2 E41Q & $\begin{array}{l}377(5120), 490(970) \\
\varepsilon_{\sigma / \pi}=5.3\end{array}$ & 154 & +510 \\
GRa3DChC2 E41A & $\begin{array}{l}373(4090), 490(720) \\
\varepsilon_{\sigma / \pi}=5.7 \\
390(7000), 490(2200)\end{array}$ & 160 & +85 \\
nitrosocyanin $^{[76,82]}$ & 142 & \\
& $\varepsilon_{\sigma / \pi}=3.2$ & & \\
\hline
\end{tabular}

ical denaturation, may have weakened the hydrophobic box meant to create an entatic state. This instability also precluded any single site mutation studies to investigate this construct, so a more stable variant was necessary. Our experience with three-stranded coiled coils led to the strategy of increasing the length of the $\alpha_{3} \mathrm{D}$ alpha helix in the scaffold protein to improve the thermodynamic stability. ${ }^{[85]}$ The initial design of the $\alpha_{3} \mathrm{D}$ scaffold by the De Grado group went through several iterations of redesign, largely centered around the loop region connecting each helix. For our design of $G R \alpha_{3} D$ we sought to avoid this complication by expanding the helices from the center and duplicating the central heptad of each. $\mathrm{GuHCl}$ denaturation of $\mathrm{GR} \alpha_{3} \mathrm{D}$ proved this strategy was successful, creating a scaffold with a free energy of unfolding of $11.4 \mathrm{kcal} \mathrm{mol}^{-1}$ compared to the $5.9 \mathrm{kcal} \mathrm{mol}^{-1}$ of the parent $\alpha_{3} \mathrm{D}$. This increased stability allowed us to grow diffraction-quality crystals and solve the structure of the scaffold to a resolution of $1.34 \AA$ (Table 8).

By designing the $\mathrm{ChC} 2$ binding center into $\mathrm{GR} \alpha_{3} \mathrm{D}$ we created $\mathrm{GR} \alpha_{3} \mathrm{DChC} 2$ and determined it to be fully folded in solution, unlike its parent peptide (Figure 14). The spectroscopic properties of the $\mathrm{Cu}^{\mathrm{II}}$ form of this construct, however, remained decidedly within the category of a red copper protein, thus negating the hypothesis that thermodynamic instability had been the cause of the aberrant spectral properties of $\alpha_{3} \mathrm{DChC} 2$. MCD deconvolution of the optical spectrum of $\mathrm{GR} \alpha_{3} \mathrm{DChC} 2$ further cemented this red copper protein assignment, matching the $\mathrm{d}-\mathrm{d}$ electronic transitions observed in native nitrosocyanin. ${ }^{[76]}$ The $\mathrm{His}_{2}$ CysGlu binding site of nitrosocyanin was not a part of our original $\alpha_{3} \mathrm{DChC} 2$ design so the question remained as to why this construct was so similar to nitrosocyanin when it was designed solely as a $\mathrm{His}_{2}$ Cys binding site.

Modeling the copper binding site of $\mathrm{GR} \alpha_{3} \mathrm{DChC} 2$ into the GR $\alpha_{3} D$ X-ray crystal structure suggested that, because the binding site was designed to span two of the three helices, the $\mathrm{Cu}$ atom would be positioned off-center from the hydrophobic interior and would likely locate more towards the helical-helical interface. This positioning of the $\mathrm{Cu}$ center would bring it within $5 \AA$ of Glu 41 , included in the $G R \alpha_{3} D$ scaffold as part of a salt bridge with $\operatorname{Arg} 24$. This was 
a particularly intriguing possibility as the absorption spectrum of $\mathrm{GR} \alpha_{3} \mathrm{DChC} 2$ resembled that of not only nitrosocyanin but the variant blue copper proteins M121E azurin and M148E rusticyanin. Thus, we hypothesized that removing this $\mathrm{Cu}-$ Glu 41 interaction through a E41A mutation or tuning it with E41Q would allow us to tune the spectroscopic properties of $\mathrm{GR} \alpha_{3} \mathrm{DChC} 2$ to that of a blue or green copper protein. ${ }^{[82,83]}$

Mutation studies around this Glu41-Arg 24 pair found that E41A and E41Q caused drastic changes to the absorption profile: blue-shifting the $\sigma$-LMCT band and increasing the $\varepsilon_{\sigma / \pi}$ value to 5.3 or 5.7 , respectively, while the hyperfine coupling constant increased to 160 or $154 \times 10^{-4} \mathrm{~cm}^{-1}$, respectively. These changes indicated a change from a red copper protein to a type $2 \mathrm{Cu}$ protein. R24A and $\mathrm{R} 24 \mathrm{M}$ constructs were made to test if the effects of the E41 mutations were caused by the loss of a salt bridge and increased solvent access rather than the loss of a direct interaction between $\mathrm{Cu}$ and E41. R24 variant constructs showed no change in the UV/Vis and EPR spectra of their $\mathrm{Cu}^{\mathrm{II}}$ forms, thus confirming that the E41A and E41Q mutations had specifcally disrupted an E41-Cu interaction. This result confirmed that our $\mathrm{GR} \alpha_{3} \mathrm{DChC} 2$ construct was best thought of as a nitrosocyanin mimic rather than a blue copper protein with a Glu ligand in the axial position. This means that tuning this construct to have the spectroscopic properties of a blue copper protein will likely require larger changes to the active site. This could possibly be achieved by mirroring a recent construct made by the $\mathrm{Lu}$ group in which the blue copper protein Azurin was mutated to a nitrosocyanin-like red copper construct through rotation of the active site and substitution of the fourth $\mathrm{Cu}$ ligand. ${ }^{[86]}$ The $\mathrm{Cu}^{\mathrm{I}}$ geometries and redox potentials were found to be invariant in all of the mutations tested within our study. This reaffirms the prior assumption that one can focus on tuning the $\mathrm{Cu}^{\mathrm{II}}$ spectroscopic properties with a reasonable expectation that this will not impact the $\mathrm{Cu}^{\mathrm{I}}$ geometry or redox potential. We have since used this new structural insight to create variants with spectroscopic properties corresponding to a green copper protein that could be tuned to a blue copper protein using chloride as an exogenous ligand-similar to the work of the Tanaka group as well as a variant that recapitulates the spectroscopic properties of blue copper proteins without the need for an exogenous ligand. ${ }^{[77 d]} \mathrm{A}$ manuscript describing this work is in preparation. ${ }^{[87]}$

\subsection{Measuring Electron-Transfer Activity}

One of the overarching goals of our group has been to create a fully functional and self-contained $\mathrm{Cu}$ nitrite reductase with an active type $2 \mathrm{Cu}$ site and an electrontransfer site. This goal requires an understanding of how electron transfer occurs through our peptides as well as the rates of electron transfer at their redox-active metal centers. To date we have explored this in two ways: using intermolecular electron transfer to study $\alpha_{3} \mathrm{DCH} 3$ and intramolecular electron transfer to look at how electrons can travel through our constructs. ${ }^{[88]}$

To investigate the electron-transfer properties of one of our cupredoxin models, solutions of $\alpha_{3} \mathrm{DCH} 3$ were photooxidized by irradiating ruthenium(II) trisbipyridine, $\left[\mathrm{Ru}^{\mathrm{II}}(\text { bipy })_{3}\right]^{3+}$, with $460 \mathrm{~nm}$ laser light in the presence of the electron acceptor $\left[\mathrm{Ru}^{\mathrm{III}}\left(\mathrm{NH}_{3}\right)_{6}\right]^{3+}$ to produce $\left[\mathrm{Ru}^{\mathrm{III}}\right.$ (bipy) $\left.)_{3}\right]^{3+}$, a powerful oxidizing agent with a reduction potential of 1.3 V. Electron transfer between different species was then followed by optical spectroscopy (Figure 15 and Table 9). In this reaction, the $\left[\mathrm{Ru}^{\mathrm{II}}(\text { bipy })_{3}\right]^{3+}$ radical is formed after $100 \mathrm{~ns}$ and this reacts with the electron acceptor to form $\left[\mathrm{Ru}^{\mathrm{III}}(\text { bipy })_{3}\right]^{3+}$ after $1 \mu \mathrm{s}$. A positive absorption band at $400 \mathrm{~nm}$ after $100 \mu \mathrm{s}$ was assigned as the formation of $\mathrm{Cu}^{\mathrm{II}} \alpha_{3} \mathrm{DCH} 3$ from the spectroscopically silent $\mathrm{Cu}^{\mathrm{I}} \alpha_{3} \mathrm{DCH} 3$. This $\mathrm{Cu}^{\mathrm{II}} \alpha_{3} \mathrm{DCH} 3$ reacted with the electron acceptor to reform $\mathrm{Cu}^{\mathrm{I}} \alpha_{3} \mathrm{DCH} 3$ after $10 \mathrm{~ms}$. Based on the changes in the absorption, we estimated that around $1.9 \mu \mathrm{M} \mathrm{Cu}{ }^{\mathrm{II}} \alpha_{3} \mathrm{DCH} 3$ was formed from $3 \mu \mathrm{M}\left[\mathrm{Ru}^{\mathrm{III}}(\text { bipy })_{3}\right]^{3+}$. Reactions using other photoactive oxidants followed similar profiles.

Kinetic analysis found that the first order rate constant of the intermolecular electron-transfer reaction between $\mathrm{Ru}^{\text {III }}$ (bipy) $)_{3}$ and $\mathrm{Cu}^{\mathrm{I}} \alpha_{3} \mathrm{DCH}$ was $1.15 \times 10^{5} \mathrm{~s}^{-1}$, four times greater than the same reaction with apo-peptide. This first order rate constant varied between 0.79 and $1.15 \times 10^{5} \mathrm{~s}^{-1}$ depending on the photooxidant used. We hypothesized that the reaction

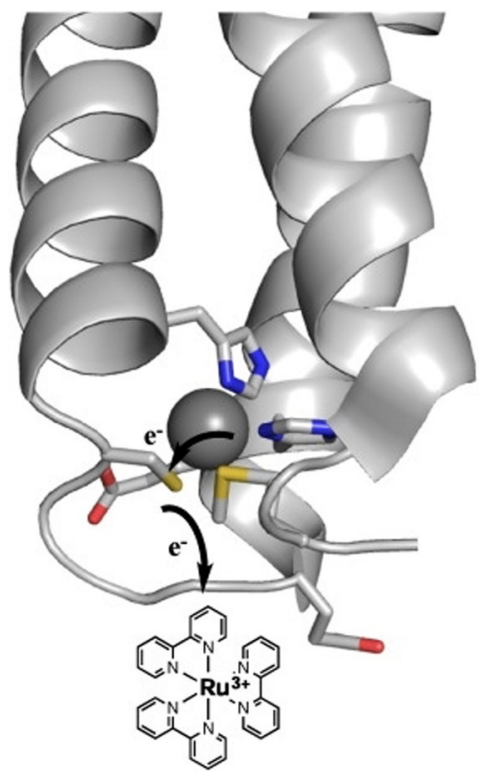

Figure 15. Proposed electron-transfer pathway. For $\mathrm{Cu \alpha 3DCH}$, the Cys residue can provide a super-exchange pathway for electron transfer between the copper center and the photooxidant. Reproduced from Ref. [88b] with permission. Copyright 2018 Elsevier B.V.

Table 9: Intermolecular electron-transfer properties of $\alpha_{3} \mathrm{DCH} 3$

\begin{tabular}{|c|c|c|c|}
\hline Sample & $\mathrm{k}_{\text {lapp }} \times 10^{5} \mathrm{~s}^{-1}$ & $\mathrm{k}_{2 \mathrm{app}} \times 10^{8} \mathrm{M}^{-1} \mathrm{~s}^{-1}$ & $\begin{array}{l}\text { Driving } \\
\text { force } \\
{[\mathrm{eV}]}\end{array}$ \\
\hline Apo $\alpha_{3} \mathrm{DCH} 3+\mathrm{Ru}(\text { bipy })_{3}$ & 0.39 & 3.9 & \\
\hline $\mathrm{Cu}_{3} \mathrm{DCH} 3+\mathrm{Ru}$ (bipy) ${ }_{3}$ & 1.15 & 6.3 & 1.18 \\
\hline $\mathrm{Cu}_{3} \mathrm{DCH} 3+\mathrm{Ru}(\text { phen })_{3}$ & 1.07 & 10.7 & 0.88 \\
\hline $\mathrm{Cu}_{3} \mathrm{DCH} 3+(\mathrm{COOEt})_{4} \mathrm{Ru}(\text { bipy })_{3}$ & 1.08 & 10.8 & 1.51 \\
\hline $\mathrm{Cu}_{3} \mathrm{DCH} 3+(\mathrm{COOEt})_{2} \mathrm{Ru}$ (bipy) ${ }_{3}$ & 1.05 & 10.5 & 1.24 \\
\hline $\mathrm{Cu}_{3} \mathrm{DCH} 3+\mathrm{ZnTMPyP}$ & 0.79 & 7.9 & 0.84 \\
\hline
\end{tabular}


between apo- $\alpha_{3} \mathrm{DCH}$ and $\left[\mathrm{Ru}^{\mathrm{III}}(\text { bipy })_{3}\right]^{3+}$ was due to the presence of redox active residues Cys 21, His 18/28, and Met 72 near the C-terminus of the peptide and, due to its relatively low potential, Cys 21 was the most likely candidate. This is consistent with native cupredoxins, in which the $\mathrm{Cu}-$ Cys bond acts as an electron conduit.

Bimolecular rate constants for the electron transfer from $\mathrm{Cu}^{\mathrm{I}} \alpha_{3} \mathrm{DCH}$ to various photooxidants was 8 to $11 \times 10^{8} \mathrm{M}^{-1} \mathrm{~s}^{-1}$, which indicates diffusion-controlled kinetics and is comparable with native cupredoxins under similar conditions, thus exemplifying the success of this de novo cupredoxin model. Finally, a comparison of rate constant with the driving force of five different photooxidants enabled us to calculate the reorganization energy of $\mathrm{Cu}_{3} \mathrm{DCH} 3$ as $1.1 \mathrm{eV}$. This is on the higher end of the range seen for native cupredoxins (0.7$1.2 \mathrm{eV}){ }^{[89]}$

By comparing with small-molecule complexes such as $\left[\mathrm{Cu}(\text { phen })_{2}\right]^{2+}$, whose geometry changes from tetrahedral to pure tetragonal with a reorganization energy of $2.4 \mathrm{eV}$, we hypothesized that $\mathrm{Cu}_{3} \mathrm{DCH}$ was likely distorting from a pseudo-tetrahedral to pseudo-tetragonal geometry. These results further emphasize that future designs should focus on forcing the $\mathrm{Cu}^{\mathrm{II}}$ geometry of the construct into an entatic state such as in native blue copper proteins, as previous studies indicate that our constructs already possess the desired $\mathrm{Cu}^{\mathrm{I}}$ geometry.

A self-contained de novo CuNiR model with type 1 and type $2 \mathrm{Cu}$ centers for electron transfer and enzymatic activity, respectively, would require an understanding of how electrons would travel through our constructs from one metal center to another. Electron transfer over long distances (ca. $30 \AA$ ) is a requirement in various biological systems, such as photosynthesis and respiration. ${ }^{[90]}$ Such long-distance transfers occur through a series of hops, which reduce the distance required for any single-electron transfer and increases the rate of the overall process. ${ }^{[91]}$ Proteins can facilitate such hops through redox-active amino acids such as Tyr and Trp. ${ }^{[92]}$ The formation of tyrosine radicals, in particular, is a vital part of photosystem II, ribonucleotide reductase, and cytochrome $c$ oxidase. ${ }^{[90]}$ Electron transfer through the formation of tyrosine radicals occurs in a proton-coupled fashion because of the large differences in the $\mathrm{p} K_{\mathrm{a}}$ values between Tyr (10) and it's radical (-2). ${ }^{[93]}$ The study of natural systems which utilize Tyr radicals is hindered by the complexity of those systems. Previous studies on the formation of Tyr radicals within a designed protein found that a single Tyr radical within an alpha-helical bundle can be stabilized through burial in the hydrophobic interior of the peptide. ${ }^{[94]}$ We covalently attached a $\mathrm{Ru}^{\mathrm{II}}(\text { bipy })_{3}$ photooxidant on the C-terminal end of our $\alpha_{3} \mathrm{DH}_{3}$ carbonic anhydrase construct to create $\alpha_{3} \mathrm{DH}_{3-}$ Rubpymal and investigate how Tyr hopping could be utilized within our systems to facilitate long-distance electron transfer (Figure 16). ${ }^{[88 \mathrm{~b}]}$ Based on the solution structure of $\alpha_{3} \mathrm{D}$, we estimated that the bound $\mathrm{Ru}$ and Tyr 70 (the closest Tyr) were about $16 \AA$ apart.

Laser flash photolysis was used to investigate the nanosecond timescale electron-transfer reaction and kinetics between the bound $\mathrm{Ru}$ and Ty 70 . The intermolecular electron transfer between the radical $\mathrm{Ru}^{\mathrm{II}}$ (bipy) ${ }_{3}$ and the electron
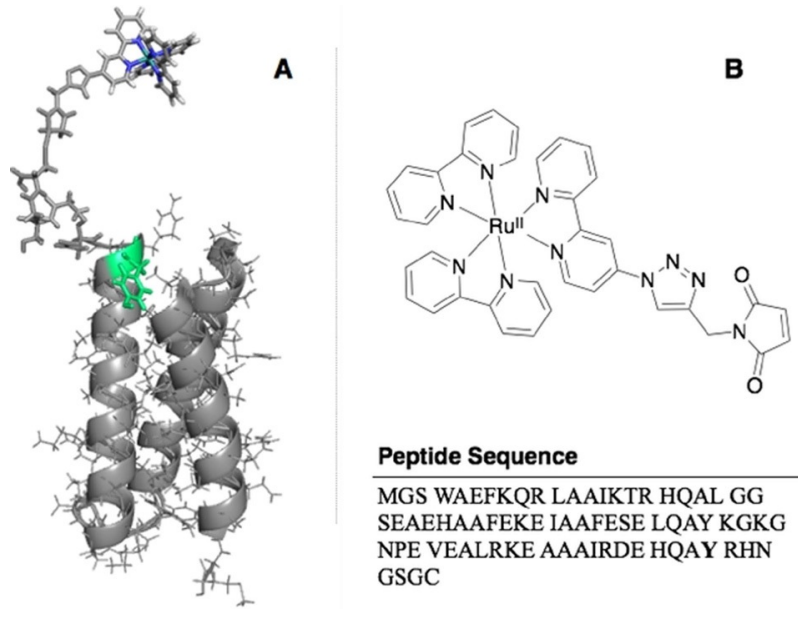

Peptide Sequence

MGS WAEFKQR LAAIKTR HQAL GG SEAEHAAFEKE IAAFESE LQAY KGKG NPE VEALRKE AAAIRDE HQAY RHN GSGC

Figure 16. A) Schematic representation of the structure of $\alpha_{3} \mathrm{DH}_{3}$ Rubpymal based on the solution NMR structure of a closely related scaffold (PDB: 2MTQ). The key tyrosine residue is marked in green. B) Chemical structure of Rubpymal (top) and sequence of $\alpha_{3} \mathrm{DH}_{3}$ (bottom). Reproduced from Ref. [88b] with permission. Copyright 2017 Wiley $\mathrm{VCH}$.

acceptor $\mathrm{Ru}^{\mathrm{III}}\left(\mathrm{NH}_{3}\right)_{6}$ produced the oxidized $\mathrm{Ru}^{\mathrm{II}}(\text { bipy })_{3}$ with a second order rate constant of $1.1 \times 10^{9} \mathrm{M}^{-1} \mathrm{~s}^{-1}$ (half-life $40 \mathrm{~ns})$. A second phase with a rate of $3.3 \times 10^{5} \mathrm{~s}^{-1}$ was determined on the basis of the observed absorption maxima at 390 and $410 \mathrm{~nm}$ to be the formation of Tyr radicals. ${ }^{[94 a, 95]}$ The observed rate is consistent with that expected for an electron transfer of $16 \AA$ based on a simplified model of electron tunneling in peptides. ${ }^{[96]}$ Finally, a third phase occurs with a half-life of $210 \mu \mathrm{s}$, in which the Tyr radical combined with the electron acceptor $\mathrm{Ru}^{\mathrm{III}}\left(\mathrm{NH}_{3}\right)_{6}$. The $\mathrm{pH}$-dependence of the second phase determined it to be a proton-coupled electron transfer (PCET), as it was four times faster at $\mathrm{pH} 9.5$ than at 5.0 and the presence of a Tyr radical was confirmed through X-band EPR spectroscopy of a reaction in the presence of the nonreversible electron acceptor [ $\mathrm{Co}^{\mathrm{III}}$ $\left.\left(\mathrm{NH}_{3}\right)_{5} \mathrm{Cl}\right]^{2+}$. Future directions of this model will be to design hydrogen-bonding amino acids around Tyr70 to investigate their effect on the observed PCET rate and the distance-dependence of designed electron-transfer relays. Refining the design of electron-transfer relays within alphahelical bundle scaffolds will bring us that much closer to our overall goal of a self-contained de novo NiR model.

\section{Summary and Outlook}

This Review summarizes our recent efforts to generate metalloprotein active sites in de novo peptides and proteins composed of three $\alpha$ helices. We have developed several models of metal binding sites with modest to excellent activity compared to the native systems. Specifically, we have, thus far, targeted the hydrolytic activity of zinc bound to symmetric $(\text { His })_{3}$ environments, copper nitrite reductase activity, and electron-transfer sites within our $\alpha$-helical scaffolds.

Our approach to generate hydrolytic activity in de novo scaffolds that model the activity of CA, by inserting a tris(his- 
tidine) metal binding environment within our well-defined scaffolds, has revealed interesting features of this enzyme. First, much of the activity arises from the symmetric primary coordination sphere being within a peptidic environment. We were able to exceed small-molecule models of CA activity by using native coordinating ligands, in a more native-like system, while still exploring the dependence of activity on the overall protein fold. Although native CA is composed primarily of beta-sheet and loop structures, our completely alien alpha-helical scaffolds described here show modest to excellent $\mathrm{CO}_{2}$ hydration and pNPA hydrolysis rates. Our next generation hydrolytic active sites will introduce asymmetry in the second coordination sphere, by formation of heterotrimers in our $3 \mathrm{SCC}$ system $^{[63]}$ or rational positioning of hydrogen-bonding residues in our $\alpha_{3} \mathrm{DH}_{3}$ system. Additionally, we can control the orientation of the amino acid residues in proximity to the metal binding site through the inclusion of non-natural amino acids or noncanonical repeats, such as stutter and stammer inserts, in the heptads.

As with the $\mathrm{Zn}(\mathrm{His})_{3}$ hydrolytic activities, the successful recapitulation of $\mathrm{CuNiR}$ activity has, thus far, only included explicit modeling of the primary coordinating ligands, namely the $\left(\mathrm{His}_{3}\right)$ environment. As with $\mathrm{CA}, \mathrm{CuNiRs}$ possess a critical acid-base hydrogen-bonding residue, Asp98, which is required for efficient proton transfer. We had attempted to include Asp in the 3SCC core near the copper site, through L19D or L26D modifications, although evidence suggested that the carboxylates interacted with each other rather than with the copper site. A consequence of working in our selfassociating $3 \mathrm{SCC}$ is that our modifications are symmetric. It may be possible to generate better $\mathrm{CuNiR}$ activities by positioning only a single Asp above or below the copper site. We have recently described a system where we should be able to make these asymmetric modifications in our 3SCC system, by forming heterotrimeric 3 SCCs. ${ }^{[63]}$ Inclusion of non-natural amino acids beyond simple methylated histidine should allow us to tune the reduction potentials and Lewis acidity of our metal binding sites.

Finally, we find it interesting to note that rubredoxin and cupredoxin both have binding sites that are comprised of loops. This allows the binding geometry to be largely dictated by the metal rather than the protein matrix. Creating the same metal coordination within the more rigid scaffold of a helical bundle likely requires exact design, which is a limiting factor in our strategy, whereby we replace leucine residues in the layers of the hydrophobic interior, severely limiting the number of geometric arrangements of ligating residues. Thus, further enhancement to the activities of our electron-transfer sites will require specific design of the loop regions that connect the helices in $\alpha_{3} \mathrm{D}$ or $\mathrm{GR} \alpha_{3} \mathrm{D}$, or a new scaffold that possesses additional inherent flexibility or secondary structure elements amenable to modification.

Protein design is a powerful tool to both challenge our understanding of metalloprotein systems and expand our knowledge of metalloenzymatic activity. The ability to recapitulate native metalloprotein function in a vastly different protein architecture, both for catalytic and electrontransfer metal sites, highlights a possible pathway for the evolutionary development of the various metalloproteins that are essential for so many cellular functions.

\section{Acknowledgements}

T.B.J.P thanks the National Science Research Council of Canada for support in the form of a Postdoctoral Fellowship. V.L.P. thanks the National Institutes of Health for financial support of this research (ES012236). Use of the Stanford Synchrotron Radiation Lightsource, SLAC National Accelerator Laboratory, is supported by the U.S. Department of Energy, Office of Science, Office of Basic Energy Sciences under Contract No. DE-AC02-76SF00515. The SSRL Structural Molecular Biology Program is supported by the DOE Office of Biological and Environmental Research, and by the National Institutes of Health, National Institute of General Medical Sciences (including P41GM103393). The contents of this publication are solely the responsibility of the authors and do not necessarily represent the official views of NIGMS or NIH.

\section{Conflict of interest}

The authors declare no conflict of interest.

How to cite: Angew. Chem. Int. Ed. 2020, 59, 7678-7699 Angew. Chem. 2020, 132, 7750-7773

[1] a) K. J. Waldron, J. C. Rutherford, D. Ford, N. J. Robinson, Nature 2009, 460, 823; b) I. Bertini, A. Sigel, Handbook on Metalloproteins, CRC Press, Boca Raton, FL, 2001; c) C. Andreini, I. Bertini, G. Cavallaro, G. L. Holliday, J. M. Thornton, J. Biol. Inorg. Chem. 2008, 13, 1205-1218.

[2] C. Andreini, I. Bertini, A. Rosato, Acc. Chem. Res. 2009, 42, $1471-1479$

[3] a) P.-S. Huang, S. E. Boyken, D. Baker, Nature 2016, 537, 320; b) F. Yu, V. M. Cangelosi, M. L. Zastrow, M. Tegoni, J. S. Plegaria, A. G. Tebo, C. S. Mocny, L. Ruckthong, H. Qayyum, V. L. Pecoraro, Chem. Rev. 2014, 114, 3495 -3578; c) Y. Lu, S. M. Berry, T. D. Pfister, Chem. Rev. 2001, 101, 3047-3080; d) Y. Lu, N. Yeung, N. Sieracki, N. M. Marshall, Nature 2009, 460, 855; e) F. Nastri, D. D'Alonzo, L. Leone, G. Zambrano, V. Pavone, A. Lombardi, Trends Biochem. Sci 2019, 44, 1022-1040.

[4] B. A. Smith, M. H. Hecht, Curr. Opin. Chem. Biol. 2011, 15, $421-426$.

[5] J. Kaplan, W. F. DeGrado, Proc. Natl. Acad. Sci. USA 2004, 101, $11566-11570$.

[6] D. N. Woolfson, G. J. Bartlett, A. J. Burton, J. W. Heal, A. Niitsu, A. R. Thomson, C. W. Wood, Curr. Opin. Struct. Biol. 2015, 33, $16-26$.

[7] a) J. P. Schneider, A. Lombardi, W. F. DeGrado, Fold. Des. 1998, 3, R29-R40; b) E. Moutevelis, D. N. Woolfson, J. Mol. Biol. 2009, 385, 726-732.

[8] B. Lovejoy, S. Choe, D. Cascio, D. McRorie, W. F. DeGrado, D. Eisenberg, Science 1993, 259, 1288-1293.

[9] R. S. Hodges, A. K. Saund, P. C. Chong, S. A. St-Pierre, R. E. Reid, J. Biol. Chem. 1981, 256, 1214-1224.

[10] G. R. Dieckmann, D. K. McRorie, D. L. Tierney, L. M. Utschig, C. P. Singer, T. V. O'Halloran, J. E. Penner-Hahn, W. F. DeGrado, V. L. Pecoraro, J. Am. Chem. Soc. 1997, 119, 61956196. 
[11] K. J. Koebke, L. Ruckthong, J. L. Meagher, E. Mathieu, J. Harland, A. Deb, N. Lehnert, C. Policar, C. Tard, J. E. PennerHahn, Inorg. Chem. 2018, 57, 12291-12302.

[12] M. L. Zastrow, A. F. Peacock, J. A. Stuckey, V. L. Pecoraro, Nat. Chem. 2012, 4, 118.

[13] J. S. Plegaria, S. P. Dzul, E. R. Zuiderweg, T. L. Stemmler, V. L. Pecoraro, Biochemistry 2015, 54, 2858-2873.

[14] R. H. Holm, P. Kennepohl, E. I. Solomon, Chem. Rev. 1996, 96, $2239-2314$

[15] a) J. Liu, S. Chakraborty, P. Hosseinzadeh, Y. Yu, S. Tian, I. Petrik, A. Bhagi, Y. Lu, Chem. Rev. 2014, 114, 4366-4469; b) S Shaik, A. W. Munro, S. Sen, C. Mowat, W. Nam, E. Derat, T. Bugg, D. A. Proshlyakov, R. P. Hausinger, G. D. Straganz, Ironcontaining enzymes: Versatile catalysts of hydroxylation reaction. in nature, Royal Society of Chemistry, London, 2011; c) R. Lill, Nature 2009, 460, 831; d) C. Andreini, V. Putignano, A. Rosato, L. Banci, Metallomics 2018, 10, 1223-1231.

[16] a) K.-H. Lee, M. Matzapetakis, S. Mitra, E. N. G. Marsh, V. L. Pecoraro, J. Am. Chem. Soc. 2004, 126, 9178-9179; b) L. Ruckthong, A. Deb, L. Hemmingsen, J. E. Penner-Hahn, V. L. Pecoraro, J. Biol. Inorg. Chem. 2018, 23, 123-135; c) A. F. Peacock, L. Hemmingsen, V. L. Pecoraro, Proc. Natl. Acad. Sci. USA 2008, 105, 16566-16571; d) A. F. Peacock, J. A. Stuckey, V. L. Pecoraro, Angew. Chem. Int. Ed. 2009, 48, 7371-7374 Angew. Chem. 2009, 121, 7507-7510.

[17] K. Håkansson, M. Carlsson, L. A. Svensson, A. Liljas, J. Mol. Biol. 1992, 227, 1192-1204.

[18] a) E. Kimura, T. Shiota, T. Koike, M. Shiro, M. Kodama, J. Am. Chem. Soc. 1990, 112, 5805-5811; b) C. P. Olmo, K. Böhmerle, H. Vahrenkamp, Inorg. Chim. Acta 2007, 360, 1510-1516 c) T. B. Koerner, R. Brown, Can. J. Chem. 2002, 80, 183-191.

[19] a) L. L. Kiefer, S. A. Paterno, C. A. Fierke, J. Am. Chem. Soc. 1995, 117, 6831-6837; b) J. F. Krebs, J. Ippolito, D. Christianson, C. Fierke, J. Biol. Chem. 1993, 268, 27458-27466; c) Z. Liang, Y. Xue, G. Behravan, B. H. Jonsson, S. Lindskog, Eur. J. Biochem. 1993, 211, $821-827$

[20] B. S. Der, D. R. Edwards, B. Kuhlman, Biochemistry 2012, 51, $3933-3940$.

[21] M. L. Zastrow, V. L. Pecoraro, J. Am. Chem. Soc. 2013, 135, $5895-5903$.

[22] A. E. Eriksson, T. A. Jones, A. Liljas, Proteins Struct. Funct. Bioinf. 1988, 4, 274-282.

[23] M. Matzapetakis, B. T. Farrer, T.-C. Weng, L. Hemmingsen, J. E. Penner-Hahn, V. L. Pecoraro, J. Am. Chem. Soc. 2002, 124 $8042-8054$.

[24] V. M. Cangelosi, A. Deb, J. E. Penner-Hahn, V. L. Pecoraro, Angew. Chem. Int. Ed. 2014, 53, 7900-7903; Angew. Chem. 2014, 126, 8034-8037.

[25] J. E. Jackman, K. M. Merz, C. A. Fierke, Biochemistry 1996, 35 , $16421-16428$

[26] D. A. Jewell, C. Tu, S. R. Paranawithana, S. M. Tanhauser, P. V. LoGrasso, P. J. Laipis, D. N. Silverman, Biochemistry 1991, 30 $1484-1490$.

[27] L. Koziol, C. A. Valdez, S. E. Baker, E. Y. Lau, W. C. Floyd III, S. E. Wong, J. H. Satcher, Jr, F. C. Lightstone, R. D. Aines, Inorg. Chem. 2012, 51, 6803-6812.

[28] K. Nakata, N. Shimomura, N. Shiina, M. Izumi, K. Ichikawa, M. Shiro, J. Inorg. Biochem. 2002, 89, 255-266.

[29] H. Slebocka-Tilk, J. Cocho, Z. Frackman, R. Brown, J. Am. Chem. Soc. 1984, 106, 2421-2431.

[30] C. A. Fierke, T. L. Calderone, J. F. Krebs, Biochemistry 1991, 30 , 11054-11063.

[31] S. Studer, D. A. Hansen, Z. L. Pianowski, P. R. Mittl, A. Debon, S. L. Guffy, B. S. Der, B. Kuhlman, D. Hilvert, Science 2018, 362, $1285-1288$.

[32] a) W. J. Song, F. A. Tezcan, Science 2014, 346, 1525-1528; b) J. D. Brodin, A. Medina-Morales, T. Ni, E. N. Salgado, X. I.
Ambroggio, F. A. Tezcan, J. Am. Chem. Soc. 2010, 132, 86108617.

[33] C. M. Rufo, Y. S. Moroz, O. V. Moroz, J. Stöhr, T. A. Smith, X Hu, W. F. DeGrado, I. V. Korendovych, Nat. Chem. 2014, 6, 303.

[34] L. Ruckthong, M. L. Zastrow, J. A. Stuckey, V. L. Pecoraro, J. Am. Chem. Soc. 2016, 138, 11979-11988.

[35] a) H. Iwasaki, S. Noji, S. Shidara, J. Biochem. 1975, 78, 355-361; b) E. Libby, B. A. Averill, Biochem. Biophys. Res. Commun. 1992, 187, 1529-1535; c) M. Kukimoto, M. Nishiyama, M. E. Murphy, S. Turley, E. T. Adman, S. Horinouchi, T. Beppu, Biochemistry 1994, 33, 5246-5252; d) M. E. Murphy, S. Turley, E. T. Adman, J. Biol. Chem. 1997, 272, 28455-28460.

[36] a) S. V. Antonyuk, R. W. Strange, G. Sawers, R. R. Eady, S. S. Hasnain, Proc. Natl. Acad. Sci. USA 2005, 102, 12041-12046; b) K. Kataoka, H. Furusawa, K. Takagi, K. Yamaguchi, S. Suzuki, J. Biochem. 2000, 127, 345-350; c) M. J. Boulanger, M. Kukimoto, M. Nishiyama, S. Horinouchi, M. E. Murphy, J. Biol. Chem. 2000, 275, 23957-23964.

[37] M. Tegoni, F. Yu, M. Bersellini, J. E. Penner-Hahn, V. L. Pecoraro, Proc. Natl. Acad. Sci. USA 2012, 109, 21234-21239.

[38] L. S. Kau, D. J. Spira-Solomon, J. E. Penner-Hahn, K. O. Hodgson, E. I. Solomon, J. Am. Chem. Soc. 1987, 109, 6433-6442.

[39] E. Prenesti, P. G. Daniele, M. Prencipe, G. Ostacoli, Polyhedron 1999, 18, 3233-3241.

[40] K. Olesen, A. Veselov, Y. Zhao, Y. Wang, B. Danner, C. P. Scholes, J. P. Shapleigh, Biochemistry 1998, 37, 6086-6094.

[41] a) F. Jacobson, A. Pistorius, D. Farkas, W. De Grip, Ö. Hansson, L. Sjölin, R. Neutze, J. Biol. Chem. 2007, 282, 6347-6355; b) S. Suzuki, K. Yamaguchi, K. Kataoka, K. Kobayashi, S. Tagawa, T. Kohzuma, S. Shidara, H. Iwasaki, J. Biol. Inorg. Chem. 1997, 2 , $265-274$

[42] E. Monzani, G. A. A. Koolhaas, A. Spandre, E. Leggieri, L. Casella, M. Gullotti, G. Nardin, L. Randaccio, M. Fontani, P. Zanello, J. Biol. Inorg. Chem. 2000, 5, 251-261.

[43] A. Warshel, P. K. Sharma, M. Kato, Y. Xiang, H. Liu, M. H. Olsson, Chem. Rev. 2006, 106, 3210-3235.

[44] S. D. Fried, S. Bagchi, S. G. Boxer, Science 2014, 346, 1510-1514.

[45] a) R. Zwanzig, J. Chem. Phys. 1992, 97, 3587-3589; b) W. Min, B. P. English, G. Luo, B. J. Cherayil, S. Kou, X. S. Xie, Acc. Chem. Res. 2005, 38, 923-931.

[46] M. R. Ross, A. M. White, F. Yu, J. T. King, V. L. Pecoraro, K. J. Kubarych, J. Am. Chem. Soc. 2015, 137, 10164-10176.

[47] M. Lim, P. Hamm, R. M. Hochstrasser, Proc. Natl. Acad. Sci. USA 1998, 95, 15315-15320.

[48] a) A. Churg, A. Warshel, Biochemistry 1986, 25, 1675-1681; b) D. Kuila, J. A. Fee, J. Biol. Chem. 1986, 261, 2768-2771; c) R. Varadarajan, T. E. Zewert, H. B. Gray, S. G. Boxer, Science 1989, 243, 69-72

[49] E. E. Chufán, S. T. Prigge, X. Siebert, B. A. Eipper, R. E. Mains, L. M. Amzel, J. Am. Chem. Soc. 2010, 132, 15565-15572.

[50] F. Yu, J. E. Penner-Hahn, V. L. Pecoraro, J. Am. Chem. Soc. 2013, 135, 18096-18107.

[51] H. B. Gray, B. G. Malmström, Comments Inorg. Chem. 1983, 2 , 203-209.

[52] a) O. Iranzo, C. Cabello, V. L. Pecoraro, Angew. Chem. Int. Ed. 2007, 46, 6688-6691; Angew. Chem. 2007, 119, 6808-6811; b) K. H. Lee, C. Cabello, L. Hemmingsen, E. N. G. Marsh, V. L. Pecoraro, Angew. Chem. Int. Ed. 2006, 45, 2864-2868; Angew. Chem. 2006, 118, 2930-2934.

[53] K. J. Koebke, F. Yu, E. Salerno, C. Van Stappen, A. G. Tebo, J. E. Penner-Hahn, V. L. Pecoraro, Angew. Chem. Int. Ed. 2018, 57, 3954-3957; Angew. Chem. 2018, 130, 4018-4021.

[54] Y. Fukuda, K. M. Tse, T. Nakane, T. Nakatsu, M. Suzuki, M. Sugahara, S. Inoue, T. Masuda, F. Yumoto, N. Matsugaki, Proc. Natl. Acad. Sci. USA 2016, 113, 2928-2933.

[55] S. T. Prigge, A. S. Kolhekar, B. A. Eipper, R. E. Mains, L. M. Amzel, Science 1997, 278, 1300-1305. 
[56] K. J. Koebke, F. Yu, C. Van Stappen, T. B. Pinter, A. Deb, J. E. Penner-Hahn, V. L. Pecoraro, J. Am. Chem. Soc. 2019, 141, $7765-7775$.

[57] M. Tanokura, Biochim. Biophys. Acta Protein Struct. Mol. Enzymol. 1983, 742, 576-585.

[58] M. Tegoni, F. Yu, M. Bersellini, J. E. Penner-Hahn, V. L. Pecoraro, Proc. Natl. Acad. Sci. USA 2012, 109, 21234-21239.

[59] K. J. Koebke, F. Yu, E. Salerno, C. V. Stappen, A. G. Tebo, J. E. Penner-Hahn, V. L. Pecoraro, Angew. Chem. Int. Ed. 2018, 57, 3954-3957; Angew. Chem. 2018, 130, 4018-4021.

[60] N. Isoda, H. Yokoyama, M. Nojiri, S. Suzuki, K. Yamaguchi, Bioelectrochemistry 2010, 77, $82-88$

[61] E. I. Tocheva, L. D. Eltis, M. E. P. Murphy, Biochemistry 2008 , $47,4452-4460$.

[62] N. G. H. Leferink, C. Han, S. V. Antonyuk, D. J. Heyes, S. E. J. Rigby, M. A. Hough, R. R. Eady, N. S. Scrutton, S. S. Hasnain, Biochemistry 2011, 50, 4121-4131.

[63] A. E. Tolbert, C. S. Ervin, L. Ruckthong, T. J. Paul, V. M. Jayasinghe-Arachchige, K. P. Neupane, J. A. Stuckey, R. Prabhakar, V. L. Pecoraro, Nat. Chem. 2019, in press.

[64] a) W. Lovenberg, B. E. Sobel, Proc. Natl. Acad. Sci. USA 1965, 54,193-199; b) P. Bertrand, J.-P. Gayda, Biochim. Biophys. Acto Protein Struct. Mol. Enzymol. 1988, 954, 347-350; c) R. G. Shulman, P. Eisenberger, W. E. Blumberg, N. A. Stombaugh, Proc. Natl. Acad. Sci. USA 1975, 72, 4003-4007; d) B. Bunker, E. A. Stern, Biophys. J. 1977, 19, 253-264; e) N. M. Atherton, K Garbett, R. D. Gillard, R. Mason, S. J. Mayhew, J. L. Peel, J. E. Stangroom, Nature 1966, 212, 590-593; f) H. Bönisch, C. L. Schmidt, P. Bianco, R. Ladenstein, J. Biol. Inorg. Chem. 2007, 12, $1163-1171$.

[65] a) S. C. Lee, W. Lo, R. H. Holm, Chem. Rev. 2014, 114, 3579 3600 ; b) D. L. Gerlach, D. Coucouvanis, J. Kampf, N. Lehnert, Eur. J. Inorg. Chem. 2013, 5253-5264.

[66] a) A. Jacques, M. Clémancey, G. Blondin, V. Fourmond, J.-M Latour, O. Sénèque, Chem. Commun. 2013, 49, 2915-2917; b) V. Nanda, M. M. Rosenblatt, A. Osyczka, H. Kono, Z. Getahun, P. L. Dutton, J. G. Saven, W. F. DeGrado, J. Am. Chem. Soc. 2005, 127, 5804-5805; c) A. Jacques, J.-M. Latour, O. Sénèque, Dalton Trans. 2014, 43, 3922-3930; d) E. Farinas, L. Regan, Protein Sci. 1998, 7, 1939-1946; e) D. E. Benson, M. S. Wisz, W. Liu, H. W. Hellinga, Biochemistry 1998, 37, 7070-7076.

[67] A. G. Tebo, T. B. J. Pinter, R. García-Serres, A. L. Speelman, C. Tard, O. Sénéque, G. Blondin, J.-M. Latour, J. Penner-Hahn, N Lehnert, V. L. Pecoraro, Biochemistry 2018, 57, 2308-2316.

[68] A. G. Tebo, L. Hemmingsen, V. L. Pecoraro, Metallomics 2015, 7, 1555-1561.

[69] Z. Xiao, M. J. Lavery, M. Ayhan, S. D. B. Scrofani, M. C. J. Wilce, J. M. Guss, P. A. Tregloan, G. N. George, A. G. Wedd, J. Am. Chem. Soc. 1998, 120, 4135-4150.

[70] a) P. Wegner, M. Bever, V. Schünemann, A. X. Trautwein, C. Schmidt, H. Bönisch, M. Gnida, W. Meyer-Klaucke, Hyperfine Interact. 2004, 156, 293-298; b) J. M. Meyer, in Handbook of Metalloproteins (Ed.: A. H. Messerschmidt, R. Poulat, T. Wieghardt), Wiley, Hoboken, 2006.

[71] a) I. Moura, A. V. Xavier, R. Cammack, M. Bruschi, J. Le Gall, Biochim. Biophys. Acta Protein Struct. 1978, 533, 156-162; b) F. E. Jenney, M. W. W. Adams, in Methods Enzymol., Vol. 334, Academic Press, San Diego, 2001, pp. 45-55.

[72] a) V. S. Oganesyan, S. J. George, M. R. Cheesman, A. J. Thomson, J. Chem. Phys. 1999, 110, 762-777; b) S. J. Yoo, J. Meyer, C. Achim, J. Peterson, M. P. Hendrich, E. Münck, J. Biol. Inorg. Chem. 2000, 5, 475-487; c) B. Börger, D. Suter, J. Chem. Phys 2001, 115, 9821 -9826; d) J. Peisach, W. E. Blumberg, E. T. Lode, M. J. Coon, J. Biol. Chem. 1971, 246, 5877-5881.

[73] E. I. Solomon, Inorg. Chem. 2006, 45, 8012-8025

[74] A. A. Gewirth, E. I. Solomon, J. Am. Chem. Soc. 1988, 110, $3811-3819$.
[75] L. B. LaCroix, S. E. Shadle, Y. Wang, B. A. Averill, B. Hedman, K. O. Hodgson, E. I. Solomon, J. Am. Chem. Soc. 1996, 118, $7755-7768$.

[76] L. Basumallick, R. Sarangi, S. DeBeer George, B. Elmore, A. B. Hooper, B. Hedman, K. O. Hodgson, E. I. Solomon, J. Am. Chem. Soc. 2005, 127, 3531-3544.

[77] a) H. W. Hellinga, J. Am. Chem. Soc. 1998, 120, 10055-10066; b) Y. Lu, L. B. LaCroix, M. D. Lowery, E. I. Solomon, C. J. Bender, J. Peisach, J. A. Roe, E. B. Gralla, J. S. Valentine, J. Am. Chem. Soc. 1993, 115, 5907-5918; c) R. Schnepf, W. Haehnel, K. Wieghardt, P. Hildebrandt, J. Am. Chem. Soc. 2004, 126, $14389-$ 14399; d) D. Shiga, D. Nakane, T. Inomata, Y. Funahashi, H. Masuda, A. Kikuchi, M. Oda, M. Noda, S. Uchiyama, K. Fukui, K. Kanaori, K. Tajima, Y. Takano, H. Nakamura, T. Tanaka, J. Am. Chem. Soc. 2010, 132, 18191-18198.

[78] D. Shiga, Y. Hamano, M. Kamei, Y. Funahashi, H. Masuda, M. Sakaguchi, T. Ogura, T. Tanaka, J. Biol. Inorg. Chem. 2012, 17, $1025-1031$.

[79] J. S. Plegaria, M. Duca, C. Tard, T. J. Friedlander, A. Deb, J. E. Penner-Hahn, V. L. Pecoraro, Inorg. Chem. 2015, 54, 94709482.

[80] S. Chakraborty, J. Y. Kravitz, P. W. Thulstrup, L. Hemmingsen, W. F. DeGrado, V. L. Pecoraro, Angew. Chem. Int. Ed. 2011, 50, 2049-2053; Angew. Chem. 2011, 123, 2097-2101.

[81] a) K. W. Penfield, R. R. Gay, R. S. Himmelwright, N. C. Eickman, V. A. Norris, H. C. Freeman, E. I. Solomon, J. Am. Chem. Soc. 1981, 103, 4382 - 4388; b) G. P. Anderson, D. G. Sanderson, C. H. Lee, S. Durell, L. B. Anderson, E. L. Gross, Biochim. Biophys. Acta 1987, 894, 386-398.

[82] D. M. Arciero, B. S. Pierce, M. P. Hendrich, A. B. Hooper, Biochemistry 2002, 41, 1703-1709.

[83] a) B. G. Karlsson, L.-C. Tsai, H. Nar, J. Sanders-Loehr, N. Bonander, V. Langer, L. Sjölin, Biochemistry 1997, 36, 40894095; b) J. F. Hall, L. D. Kanbi, R. W. Strange, S. S. Hasnain, Biochemistry 1999, 38, 12675-12680.

[84] a) T. Pascher, B. G. Karlsson, M. Nordling, B. G. Malmstom, T. Vanngard, Eur. J. Biochem. 1993, 212, 289-296; b) A. G. Lappin, C. A. Lewis, W. J. Ingledew, Inorg. Chem. 1985, 24, 1446-1450; c) F. Xu, R. M. Berka, J. A. Wahleithner, B. A. Nelson, J. R. Shuster, S. H. Brown, A. E. Palmer, E. I. Solomon, Biochem. J. 1998, 334, $63-70$.

[85] a) B. T. Farrer, N. P. Harris, K. E. Balchus, V. L. Pecoraro, Biochemistry 2001, 40, 14696-14705; b) J. Y. Su, R. S. Hodges, C. M. Kay, Biochemistry 1994, 33, 15501-15510.

[86] S. Tian, J. Liu, R. E. Cowley, P. Hosseinzadeh, N. M. Marshall, Y. Yu, H. Robinson, M. J. Nilges, N. J. Blackburn, E. I. Solomon, Y. Lu, Nat. Chem. 2016, 8, 670-677.

[87] K. J. Koebke, T. B. J. Pinter, A. Deb, C. Tard, J. Penner-Hahn, V. L. Pecoraro, unpublished results.

[88] a) J. S. Plegaria, C. Herrero, A. Quaranta, V. L. Pecoraro, Biochim. Biophys. Acta Bioenerg. 2016, 1857, 522-530; b) A. G. Tebo, A. Quaranta, C. Herrero, V. L. Pecoraro, A. Aukauloo, ChemPhotoChem 2017, 1, 89-92.

[89] a) J. R. Winkler, P. Wittung-Stafshede, J. Leckner, B. G. Malmström, H. B. Gray, Proc. Natl. Acad. Sci. USA 1997, 94, $4246-$ 4249; b) A. J. Di Bilio, M. G. Hill, N. Bonander, B. G. Karlsson, R. M. Villahermosa, B. G. Malmström, J. R. Winkler, H. B. Gray, J. Am. Chem. Soc. 1997, 119, 9921-9922; c) L. K. Skov, T. Pascher, J. R. Winkler, H. B. Gray, J. Am. Chem. Soc. 1998, 120, 1102-1103; d) K. Sigfridsson, M. Ejdebäck, M. Sundahl, Ö. Hansson, Arch. Biochem. Biophys. 1998, 351, 197-206; e) T. M. McCleskey, J. R. Winkler, H. B. Gray, J. Am. Chem. Soc. 1992, 114, $6935-6937$.

[90] J. L. Dempsey, J. R. Winkler, H. B. Gray, Chem. Rev. 2010, 110, $7024-7039$

[91] a) H. B. Gray, J. R. Winkler, Chem. Phys. Lett. 2009, 483, 1-9; b) H. B. Gray, J. R. Winkler, Q. Rev. Biophys. 2003, 36, 341-372; 
c) C. C. Moser, J. M. Keske, K. Warncke, R. S. Farid, P. L. Dutton, Nature 1992, 355, 796-802.

[92] B. A. Barry, J. Photochem. Photobiol. B 2011, 104, 60-71.

[93] W. T. Dixon, D. Murphy, J. Chem. Soc. Faraday Trans. 2 1976, 72, $1221-1230$.

[94] a) B. W. Berry, M. C. Martínez-Rivera, C. Tommos, Proc. Natl. Acad. Sci. USA 2012, 109, 9739-9743; b) S. D. Glover, C. Jorge, L. Liang, K. G. Valentine, L. Hammarström, C. Tommos, J. Am. Chem. Soc. 2014, 136, 14039-14051.

[95] a) L. P. Candeias, S. Turconi, J. H. A. Nugent, Biochim. Biophys. Acta Bioenerg. 1998, 1363, 1-5; b) A. A. Pizano, D. A. Lutter- man, P. G. Holder, T. S. Teets, J. Stubbe, D. G. Nocera, Proc. Natl. Acad. Sci. USA 2012, 109, 39-43.

[96] C. C. Moser, P. L. Dutton, Biochim. Biophys. Acta Bioenerg. 1992, 1101, 171-176.

Manuscript received: June 16, 2019

Accepted manuscript online: August 22, 2019

Version of record online: March 2, 2020 